\title{
Über den Einfluss der Luftdruckveränderungen auf die Zusammensetzung des Blutes.
}

\author{
II. Mitteilung. \\ Über- und Unterdruckatmung bei Tieren \\ Verhältnis zwischen Blutzusammensetzung und Atemtypus). \\ Von \\ Dr. Kokichi Izumiyama. \\ (泉 \\ (Aus der chirwrgischen Tniversitätsklinik zu Sendai. \\ Direlitor : Prof. Dr. St. Sekiguchi.)
}

Inhalt.

Einleitung.

Verbemerkung ïber meine Experimente:

$\$$ Über die Narkose bei den Experinenten.

$\$$ Einrichtung meiner Experimente.

$\$$ Beobachiungsmethode der Atemrerinderung.

$\$$ Blutentnahme.

$\$$ Messung der Blutbestandteile.

Resultat der Experimente.

A. Verïnderung der Blutkonzentration beim Überdruckatmen (Sauerstoff und Luft).

1). Verïnderung der Atmungskurve beim Überdruckatmen.

C. Verhältnis von Atmungstypus und Blutkonzentration beim Überdruckatmen.

D. Verïnderung der Blutkonzentration biem Unterdruckatmen.

F. Verbältnis von Atmungstypus und Blutzusammensetzung beim Unterdruckatmen.

F. Fintliisse der Einrichtung der Experimente und Blutentnahme selbst.

(i. Einfliisse ron reinem Sauerstoff auf Atmungstypus und Blut.

Deutung der Ergebnisse und Schlussfolgerung.

Literaturrerzejchnis.

\section{Einleitung:}

Wenn man bei Menschen Uberdruckatmen (vermittelst des Sauerstoffüberdruckapparates nach Tiegel) herbeiführt, verursacht es schon einige Minuten nach der Anwendung Verminderung der Blutbestandteile, 
d.h. Verdünnung des Blutes. Als Ursache davon habe ich in meiner ersten Mitteilung (1) (2) die Erscheinung hervorgehoben, dass der Gewebssaft ins Blutgefäss eindringt. Die Schlussfolgerung war, dass dies nichts weiter ist als physiologische Anpassungsfähigkeit, die, wenn die Atmungsoberfläche der Lunge gezwungener Weise mit Sauerstoff gefüllt wird, von selbst entsteht, kurz, Regulation der Atmungsoberfläche des Blutes ist.

Es ist allgemein bekannt, dass jeder Organismus die Fähigkeit hat, veränderte Atembewegungen prompt und regelmässig auszuführen, im Moment, wo Partialdruck von Sauerstoff in den Alveolen stattfindet, damit er den für den Verbrennungsprozess nötigen Sauerstoff aufnehmen kann. Dies nennt man Kompensation der Atmungsoberfläche der Lunge, deren Mittel Atmungsbewegung ist.

Neuerdings hat die Forschung auf dem Gebiet des Blutgases einen grossen Fortschritt gemacht, vor allem sind viele eingehende Untersuchungen über Blutgas beim Unterdruckatmen oder beim Atmen von sauerstoffarmer Luft und über seine Beziehungen zu den verschiedenen Atemtypen veröffentlicht worden. Auf dem Gebiet der physiologischen Pathologie über Zunahme der Atemzahl haben wir Mitteilungen in Bezug auf Steigerung des CH in Blut oder Verïnderung der Erregbarkeit des Atemzentrums, die von ungenügender Sauerstoffzufuhr herrührt.

Abgesehen von der Frage, ob und inwiefern alle diese Forschungen physiologischen Wert haben, kann man doch als Tatsache annehmen, dass mit der Zunahme der Kohlensäure die Tiefe der Atemzüge grösser, dann parallel der allmählichen Sanerstoffverminderung zuerst die Atemzüge, dann die Atemzahl immer grösser werden, danach rhythmische zuletzt oberflüchliche Atmung eintritt. Es ist kein Zweifel, dass diese Veränderung der Atemtypen mit dem Kohlensïuregehalt im Blut oder mit der Verminderung des Sauerstoffes genau Schritt hält, so dass beides gegeneinander ganz präzis wirkt. Jenes Cheyne-Stokessche Respirationsphänomen kann einzig und allein aus dieser Tatsache erklärt werden.

Wäre angesichts solcher exakten Regulationsfähigkeit, die die Atmungsoberfläche der Lunge hat, eine zweite nämlich, Veränderung der Atmungsoberfläche des Blutes, nicht überflüssig? Welcher Grund liegt dazu vor? Und in welchem Fall wird solche Regulation notwendig? Das sind die Fragen, auf deren Beantwortung mein Interesse gerichtet ist. Es fehlt freilich nicht an Physiologen, die über den Partialdruck des Sauerstoffes während längerer Zeitdauer Beobachtungen gemacht haben, von denen aber meine Untersuchung ganz unabhängig ist, denn was ich wissen wollte, war die Frage, wie sich die vom zu- und abnehmenden Atemdruck 
beeinflussten Blutzusammensetzung innerhalb einer ganz kurzen Zeit verandert.

In meiner ersten Mitteilung habe ich schon über die Literatur, die die Frage der Veränderung des Atemdruckes und der damit in Zusammenhang stehenden Blutzusammensetzung der roten Blutzellen eine allgemeine Übersicht gegeben, weshalb ich hier von weiterer Wiederholung absehe. Ich werde mich, zwecks Orientierung über den Fortschritt auf diesem Gebiet, nur darauf beschränken, einige ganze neue, direkt die Kompensationsfrage des Blutes berührende Ergebnisse ergänzend hinzuzufügen.

Im Jahre 1925 veröffentlichten Moog und Pelling ${ }^{3}$ eine Mitteilung über den Einfluss des künstlichen Pneumothorax auf die Rotenblutbilder. Der Zweck ihrer Untersuchung war der, festzustellen, ob die Zunahme der roten Blutkörperchen regulatorisch stattfünde, wenn die vom Pneumothorax herbeigeführte A temnot den Sauerstoffmangel verursacht. Das Ergebnis zeigte, dass im Tierexperiment diese Erscheinung sehr stark auftrat, und dass dagegen beim Menschenversuch das Resultat negativ ausfiel. Im Versuch mit Hunden erzielte man die gleichen Ergebnisse trotzdem Sauerstoff-Inhalation bei den an Sauerstoffmangel leidenden Hunden unternommen wurde, konnte eine Zunahme der roten Blntkörperchen niemals wieder erreicht werden. Deshalb scheint es zweifelhaft, dass die regulatorische Wirkung durch Blutkörperchen bedingt ist.

Dünner und Mecklenburg ${ }^{\text {t) }}$ bestritten diese Meinung und behaupteten, beim menschlichen Körper könne unmöglich durch therapeutisch anwendbare Druckhöhe vollkommen einseitiger Pheumothorax hervorgerufen werden, ja es sei sogar nicht ausgeschlossen, dass im Fall entzündlicher Verwachsungen Lungenkollaps entstehen kann. Die Folge wird sein, dassder Gasaustausch vermöge vollkommener Regulation der anderseitigen Pleurahöhle garnicht über die physiologische Grenze hinaus geht, so dass von Sauerstoffmangel keine Rede sein kann. Der Grund, warum in Hundeexperiment das Blutbild durch Sauerstoff-Inhalation wiederhergestellt wird, kann auch darin gefunden werden, dass bei Hunden, anders als bei Menschen, der Pneumothorax im allgemeinen auf beiden Seiten der Brusthöhle stattfindet und deshalb immer von hochgradiger Dyspnoë begleitet wird, so dass diese nicht mehr durch Sauerstoff-Inhalation zu überwinden ist.

Ich hatte früher eine ausführliche Mitteilung über die Atembewegungen des Pneumothorax ${ }^{5)}$ veröffentlicht, worin ich die Tatsache betonte, dass selbst den Pneumothorax verhältnismüssig gut ertragende Kaninchen oft von Dyspnoë befallen werden. Ich erklärte auch dabei, dass der Gasaustausch beim Pneumothorax mit der Beschaffenheit des Mediastinums und 
der kompensatorischen Amplitudevergrösserung der Atembewegung in innigem Verhältnisse steht. Wenn ich mir auch hier eine Vermutung zu äussern erlauben darf, möchte ich sagen, dass die Vermehrung und Verninderung der roten Blutzellen ausschliesslich davon abhängt, ob die Kompensationsaktionkraft der Atemberwegungen, mit andern Worten, die Erweiterung der Atemoberflüche der Lunge wirknngsvoll ausgeführt wird oder nicht.

Die Grundzüge der hier darzustellenden Untersuchung habe ich schon in der 25. Sitzung des chirurgischen Kongresses in Japan vorgetragen; an demselben Tage, d.h. in der 6. Sitzung des medizinischen Kongresses in Japan, teilte Motek $\mathrm{i}^{\mathrm{i}}$ das Ergebnis seiner Untersuchung über die Veränderung der Blutzusammensetzung beim Hochdruckatmen der Kaninchen mit. Dieses stimmte zum Teil meiner ersten sowie mit dieser Mitteilung überein, wenn er auch die Frage über die Bedeutung und das Wesen dieser Erscheinung gar nicht berührte.

Der Hauptzweck meiner Arbeit ist festzustellen :

1. $\mathrm{Ob}$ bei Tieren (Hunden und Kaninchen) wie bei Menschen die Verdünnungserscheinung des Blutes durch Sauerstoffüberdruckatmen hervorgerufen wird.

2. Ob dieselbe Erscheinung auch gleichfalls durch Luftüberdruckatmen hervorgerufen wird.

Das Ergebnis meiner Untersuchung war positiv. Darum ging ich noch weiter, indem ich genau nachzuweisen versuchte, dass diese Erscheinung als Regulation der Atmungsoberfläche des Blutes anzuschen ist.

$\mathrm{Zu}$ diesem $Z$ weck wollte ich erst folgende weitere Fragen experimentell beantworten :

3. Wird die Verdünnungserscheinung des Blutes durch Überdruckatmen selbst im Fall der Anämie, d. h., wenn die roten oder die weissen Blutkörperchen geringer an Zahl sind, hervorgerufen?

4. Kommt diese Erscheinung auch durch reines Sauerstoffatmen (atmesphären Druck) zustande?

5. Wird im Gegenteil durch Unterdruckatmen Verdickung des Blutes verursacht?

6. Welche Beziehung haben die beiden Kompensationserscheinungen der Atmungsoberfläche (Atmung und Bluthonzentration) bei Uber- und Unterdruckatmen zueinander?

7. Welches sind die Beziehungen beider Kompensationserscheinungen der Atmungsoberfläche am Schluss des Über- und Unterdruckatmen zueinander? 


\section{Vorbemerkungen über meine Experimente.}

$\$$ Versuchstiere :

Nur gut gewachsene Kaninchen und Hunde wurden gebraucht.

$\S$ Über die Narkose bei den Experimenten :

Allgemein bekannte Tatsache ist es, dass Narkotika auf die Erregbarkeit des Atemzentrums einigen Einfluss ausüben. Es wird angenommen, dass schon der Gebrauch von Hypnotika, z. B. Morphin, Veronal u. a., die Kohlensäure-Spannung in den Lungenalveolen vermehrt. Eisenhard t ${ }^{8}$ sagt, dass bei Kaninchen Chloroform, Äther usw. nicht als Tiefnarkose wirken ; sogar Chloralhydrat, wenn es in ungenügender Menge gebraucht wird, verursache nur frequentes Atmen, das allerdings nach A. Fraekel ${ }^{9)}$ durch Beigabe einer kleinen Dose Morphin abgeschwächt werden soll. Deshalb unternahm ich meine Experimente möglichst ohne Narkose der Tiere. Genauer : ich fixierte, ehe ich das Experiment anfing, das Tier auf dem Operationstisch bäuchlings, wandte die Maske an und liess es so 10-20 Minuten lang ruhig liegen, damit es sich vollständig an die Umgebung gewöhnen konnte. Erst nach solcher mehrmaligen Vorübung schritt ich zur eigentlichen Untersuchung. Dies Mittel war insofern wertvoll, als das Tier unter der angewendeten Höhe der Überdruckatmung gewöhnlich im Atmen nicht gestört wurde und ruhig und ohne Quallen blieb. Nur bei Hunden musste ich manchmal wegen ihrer Erregbarkeit Urethan- und Morphin-Narkose zu gleicher Zeit benutzen.

Dass ich bei den meisten meiner Versuch die Atmungskurve registrieren liess, trug nicht wenig dazu bei, eventuelle nervöse Einflüsse sofort und exakt zu erkennen. War dies der Fall, hörte ich selbstverständlich mit dem Versuche auf.

Ich muss nochmals ausdrücklich betonen, dass die Registrierung der Atemkurve nicht nur den Hauptzweck des Experimentes, d. h. die Veränderung der Atemtypen, sondern auch die eventuell vorhandenen nervösen Beeinflussungen, klar anzeigt.

$\$$ Einrichtung meiner Experimente.

Wie gesagt, wurde das Tier in Bauchlage fixiert. Beim Sauerstoffüberdruckatmen wurde der Tiegelsche Apparat wie bei Menschen benutzt. Bei Luftüberdruckatmen wurde der Zufuhrkanal des Apparates mit einer Glasglocke von 13,000 ccm Inhalt verbunden, deren Druckquelle von einer Rotationsluftpumpe gespeist w'urde und deren Drehungsgeschwindigkeit vermittelst des damit verbundenen Rheostats reguliert wurde. Die Maske war einzeln für beide Tiergattungen in Bereitschaft. Was hier- 
bei sehr wichtig ist, ist der Durchmesser des Ausführungskanals, der wenigstens etwas grösser als der Umfang der Luftröhre des betreffenden Tieres sein muss. Der Grund liegt darin, dass die Ventilation möglichst frei gelassen werden muss, um etwaige Kohlensäurestauung zu verhüten.

Im Fall des Unterdruckatmens wurde der Zufuhrkanal der Pumpe vom Ausfuhrkanal abgelöst ; innerhalb der Glasglocke war eine beliebige Unterdruckquelle angebracht; überflüssig zu bemerken, dass der Ausführungskanal oberhalb der Wasserfläche blossgelegt wurde.

$\$$ Beobachtungsmethode der Atemverändernng:

Atemkurve wurde registriert. $\mathrm{Zu}$ diesem $\mathrm{Zweck}$ wandte ich keine Trachealkanüle an, sondern benutzte direkt die Maske mit dem Druckdifferenzapparat ; es wurde nämlich in den Zufuhrkanal an einer $3 \mathrm{~cm}$ von der Maske entfernten Stelle ein T-Rohr hineingesteckt, das wieder in ein Quecksilbermanometer geleitet wurde (bei Kaninchen benutzte ich ein Wassermanometer), um die Veränderung des Innendruckes der Maske zu registrieren.

Die Form der auf diese Weise aufgeschriebenen Kurve zeigte keine grosse Verschiedenheit gegenüber der der Trachealkanüle (allerdings war die absolute Druckhöhe ein bisschen geringer). Diese Methode hat, verglichen mit der Kanüle-Methode, zwei Vorteile; erstens, dass dadurch eine durch den operativen Eingriff verursachte Verblutung verhindert wird, zweitens, dass das Tier vor Schmerz infolge der Operation geschützt wird.

$\S$ Blutentnahme:

Arterien-, Venen- oder Kapillarblut wurde entnommen : zu diesem Zweck rasierte ich dem Tiere die Haare am Ohrrand weg, schnitt in Arterien oder Venen, nachdem ich diese vorher operativ blossgelegt hatte, und drückte sie leise mit der Pean'schen Klemme. Bei der Kapillarblutentnahme machte ich an einer Stelle mit wenigen grossen Blutgefässen einen flachen schmalen Schnitt, der dem Unfang der Spitze der Klemme entsprach.

Bei dieser Methode brauchte ich nur die Klemme zu öffnen, um bequem und schnell das nötige Blut zu entnehmen. Es war ebenfalls praktisch zum sicheren Gelingen stets dasselbe Verfahren der Blutentnahme und ohne jeden Blutverlust anzuwenden.

$\S$ Messung der Blutbestandteile :

Die schon in der ersten Mitteilung beschriebene Methode und Apparat, wurden auch diesmal angewandt.

Bei den einzelnen Druckdifferenzexperimenten liess ich einige Minuten lang unter atmosphären Druck die normale Kurve aufschreiben. Frst 
nachdem die Atemzüge vollständig ruhig geworden, wurde der Über- oder Unterdruck appliziert. Im Verlauf des Versuches wählte ich die passenste Zeit, um die Klemme aufzumachen und das Blut zu entnehmen. Selbst beim Aufschreiben der Normalkurve vergass ich nicht, eine ganz kleine Menge Luft in die Maske einzuführen, ausserdem dort noch den Rheostat und Hahn anzubringen, damit der Innendruck der Maske und der atmosphäre Druck immer gleichmässig reguliert wurden. Solche Massregeln sind unbedingt zu treffen, denn selbst wenn der geöffnete Zufuhrkanal die Verbindung nach aussen herstellt, ist ein Zustand, den W. Müller ${ }^{10)}$ "Atmung in abgesperrtem Raum" nannte, unvermeidlich, weil keine Luft eingeführt wird; die Folge davon ist, dass schon in einigen Sekunden Mangel an Sauerstoff eintritt und zu gleicher Zeit Kohlensäureanhäufung und schliesslich Verminderung des gesamten Gasvolumens. Hough ${ }^{11)}$ und Leindö $\mathrm{rfer}^{12)}$ behaupteten auf Grund ihrer Menschenversuche, dass im abgesperrten Raum zuerst Zunahme der Atemtiefe, dann Verminderung der Atemzahl und direkt darnach reflektorisch Zunahme der Atemzahl auf kurze Zeit eintreten.

Nach obigen Vorschriften liess ich die normale Kurve registrieren, und sah dabei, dass die ruhigen Atemzüge des betreffenden Tieres immer aufrechterhalten wurden, mit Ausnahme der Atemzahl, die geringe Abnahme aufwies. Im höchsten Fall zeigte der Hund per Minute 8-10, das Kaninchen hingegen 30-35.

Ich versäumte auch nicht verschiedene Kontrollversuche zu machen, von denen später die Rede sein wird, damit mir diese bei der Deutung der Resultate meiner Experimente nützlich wären.

\section{Resultate der Experimente.}

Meine Experimente fielen in die Zeit von Mitte Dezember 1924 bis Ende September 1925, umfassten also dreiviertel Jahr und gingen durch alle klimatischen Stadien, strenge Kälte, Frühlingsmilde, Sommerhitze und dann wieder in den Herbst hinein. Die Zahl der behandelten Tiere betrug 29 Hunde und 25 Kaninchen, die der Experimente 62. Für die einzelnen Fälle wurde Messung der Blutzusammensetzung und Registrierung der Atmungskurve unternommen. Es wurde zu weit führen, wenn ich hier alle einzelnen Fälle eingehend erörtern wollte. Aber weil die feinen Veränderungen der Blutbestandteile und besonders das gegenseitige Verhältuis von diesen und der Atmungskurve zu wichtig sind, um übersehen zu werden, will ich hier möglichst genau einige typische Fälle erwähnen, 
und beschränke ich mich hier auf eine zusammenfassende Beschreibung der hauptsächlichsten Punkte, die sich aus meinen Versuchen ergaben.

\section{A. Veränderung der Blutkonzentration beim Über- druckatmen (Sauerstoff und Luft).}

Aus dem Versuche ist zu schliessen : das Uberdruckatmen von ca. 20 ccm verursacht in den meisten Fällen, bei Hunden sowie Kaninchen unverkennbare Verdünnungserscheinung des Blutes, wie das auch bei Menschen der Fall ist. Es ist auch möglich, dass diese fehlt, z. B. bei Anämie (bei Hunden unter $80 \%$ Hämoglobingehalt, bei Kaninchen unter $60 \%$ ), oder bei öfterer Wiederholung des Überdruckatmens bleibt diese Erscheinung gar aus oder ist nur in höchst geringem Grade da. Als ich bei beiden Tiergattungen vergleichende Studien anstellte, konnte ich einige Verschiedenheiten in ihrem Ausdruck entdecken. Die sich voneinander unterscheidenden Merkmale sind :

1. Die Blutverdünnungserscheinung beim Überdruckatmen erfolgt bei Hunden verhältnismässig schnell, und erreicht in 2-3 Minuten nach dem Verhalten oder in 20 Minuten das Verdünnungsmaximum, das sich dann bis zum Ende des Überdruckatmens in demselben Zustand hält:

Versuch 5. Hund Nr. 4, brïunlich, 13,3 kg. Obne Narkose. 27. Januar 1925, Zimmertemperatur $15^{\circ} \mathrm{C}$. Luftuberdruck $16-13 \mathrm{~cm}$ (Wasser), 20 Minuten lang. Blutentnahme aus Ohrarterie (kleine Menge von Kapillarblut beigemischt).

\begin{tabular}{|c|c|c|c|c|}
\hline Zeit & $\begin{array}{l}\text { Zahl d. rot. } \\
\text { Blutkörperchen }\end{array}$ & $\begin{array}{l}\text { Hämoglobin- } \\
\text { gehalt }\end{array}$ & $\begin{array}{c}\text { Serumchlorid } \\
(0.0)\end{array}$ & $\begin{array}{l}\text { Blutzucker } \\
\quad(0 \%)\end{array}$ \\
\hline $2^{\circ} 35^{\prime}$ p.m. & $6,228,000 \ldots$ & 92 (Sahli) & 0,535 & 0,218 \\
\hline $\begin{array}{l}40 \\
42\end{array}$ & $\begin{array}{l}\text { Beginn des Ube } \\
6,010,000\end{array}$ & $\begin{array}{l}\text { ruckatmens. } \\
\$ 6\end{array}$ & 0,558 & 0,109 \\
\hline $3^{\prime \prime} 0$ & $5,900,000$ & 85 & 0,558 & 0,103 \\
\hline " $\begin{array}{r}3 \\
20\end{array}$ & $\begin{array}{c}\text { Schluss des Cbe } \\
5,940,000 \\
6,336,000\end{array}$ & $\begin{array}{l}\text { ruckatmens. } \\
\quad 90 \\
85\end{array}$ & $\begin{array}{l}0,529 \\
0,529\end{array}$ & $\begin{array}{l}0,063 \\
0,134\end{array}$ \\
\hline
\end{tabular}

2. Hingegen bei Kaninchen geschieht es nur selten, dass die Verdünnungserscheinung so schnell wie bei Hunden ihren höchsten Grad erreicht; in den meisten Fällen erfahren die Blutbestandteile noch keine bedeutende Veränderung, sondern nur im Lauf der Zeit wird das Blut allmählich verdünnt : 
Versuch 24. Kaninchen Nr. 5, ㅇ. Ohne Narkose. 6. Februar 1925, Zimmertemperatur $18^{\circ} \mathrm{C}$. Luftuiberduck $20 \mathrm{~cm}$ (Wasser), 40 Minuten lang. Blutentnahme aus Kapillaren (venöses Blut beigemischt).

\begin{tabular}{|c|c|c|c|c|}
\hline Zeit & $\begin{array}{l}\text { Zahl d. rot. } \\
\text { Blutkör- } \\
\text { perchen }\end{array}$ & $\begin{array}{l}\text { Hïmoglo- } \\
\text { bingehalt } \\
\text { (Sahli) }\end{array}$ & $\begin{array}{l}\text { Serum- } \\
\text { eiweiss } \\
(\%)\end{array}$ & $\begin{array}{l}\text { Serum- } \\
\text { chlorid } \\
(\%)\end{array}$ \\
\hline $\begin{array}{l}\text { Vor d. Überdruck } \\
5 \text { Minuten später }\end{array}$ & $\begin{array}{l}6,980,000 \\
6,810,000\end{array}$ & $\begin{array}{l}88 \\
88\end{array}$ & 5,684 & $\underline{0,633}$ \\
\hline $15 \quad " \quad "$ & $6,050,000$ & 83. & 5,466 & 0,637 \\
\hline $25 \quad "$ & $6,150,000$ & 85 & - & - \\
\hline $40 \quad " \quad "$ & $5,830,000$ & 79 & 5,357 & 0,637 \\
\hline $\begin{array}{l}8 \text { Minuten nach d. Schluss des } \\
\text { Überdruckes }\end{array}$ & $7,390,000$ & 90 & & - \\
\hline 30 Minuten & $7,070,000$ & 86 & 5,466 & 0,689 \\
\hline
\end{tabular}

3. Verdünnungsgrad : bei Hunden ist der Hb.-Gehalt höchstens 18 (Sahli), durchschnittlich 8 ; bei Kaninchen höchstens 12 (Sahli), durchschnittlich 7 .

Verminderungsgrad des Serumweisses: bei Hunden höchstens 0,540\% durchschnittlich 0,352\% ; bei Kaninchen höchstens 0,540\%, durchschnittlich $0,335 \%$.

4. Serumchlorid wird im Gegensatz dazu sehr oft gegen Ende des Uberdruckatmens vermehrt ; bei Hunden Zunahme um höchstens 0,182\%, durchschnittlich $0,051 \%$; bei Kaninchen höchstens um 0,105\%, durchschnittlich $0,043 \%$.

5. Der Verdünnungsgrad des Blutes entspricht nicht immer der Stärke des Druckes. Es passiert auch, dass verhältnismässig grosser Druck keine Blutverdünnung, oder nur sehr geringe mit sich bringt. Es ist bemerkenswert, dass selbst in diesen Fällen das Blut nach dem Aufhören des Druckatmens temporäre Verdickungserscheinung zeigt :

Versuch 9. Hund Nr. 11, ₹, rötlich-brüunlich, 12,3 kg. Ohne Narkose. 5. Mürz 1925, Zimmertemperatur $20^{\circ} \mathrm{C}$. Luftüberdruck $45-50 \mathrm{~cm}$ (Wasser), 30 Minuten lang. Blutentnahme aus Kapillaren. Atemkurve Fig. 2.

\begin{tabular}{|c|c|c|c|c|c|}
\hline Zeit & $\begin{array}{l}\text { Hümoglo- } \\
\text { bingehalt }\end{array}$ & $\begin{array}{l}\text { Serum- } \\
\text { eiweiss } \\
(\%)\end{array}$ & $\begin{array}{l}\text { Serum- } \\
\text { chlorid } \\
(\%)\end{array}$ & $\begin{array}{l}\text { Atemzahl } \\
\text { (per } \\
\text { Minute) }\end{array}$ & $\begin{array}{l}\text { Atemtiefe } \\
\text { (mm) }\end{array}$ \\
\hline $\begin{array}{l}0^{\circ} 45^{\prime} \text { p.m. } \\
1^{\circ} 0^{\prime}\end{array}$ & $\begin{array}{c}102 \text { (Sahli) } \\
\text { Beginn de }\end{array}$ & $\begin{array}{c}6,984 \\
\text { berdruck }\end{array}$ & 0,529 & 14 & 7 \\
\hline $\begin{array}{lr}" & 2 \\
" & 5 \\
" & 30\end{array}$ & $\begin{array}{l}96 \\
96 \\
96\end{array}$ & $\begin{array}{l}6,984 \\
6,084\end{array}$ & $\begin{array}{l}\overline{552} \\
0,559\end{array}$ & $\underset{7}{13}$ & $\begin{array}{c}3-1 \\
\text { unklar } \\
2-3\end{array}$ \\
\hline $2_{2}^{\prime \prime} 32$ & $\begin{array}{l}\text { Sch } \\
100 \\
102\end{array}$ & $\begin{array}{l}\text { erdruck } \\
7,092 \\
7,092\end{array}$ & $\begin{array}{l}0,559 \\
0,524\end{array}$ & $\begin{array}{l}13 \\
14\end{array}$ & $\begin{array}{l}7 \\
7\end{array}$ \\
\hline
\end{tabular}


Versuch 28. Kaninchen Nr. 12, $\delta, 2135 \mathrm{~g}$. Ohne Narkose. 16. Februar 1925, Zimmertemperatur $20^{\circ} \mathrm{C}$. Luftüberdruck $20 \mathrm{~cm}$ (Wasser), 5 Minuten lang. Blutentnahme aus Kapillaren.

\begin{tabular}{|c|c|c|c|c|c|}
\hline Zeit & $\begin{array}{c}\text { Atemzahl } \\
\text { (per } \\
\text { Minute) }\end{array}$ & $\begin{array}{l}\text { Atemtiefe } \\
(\mathrm{mm})\end{array}$ & $\begin{array}{c}\text { Hämoglo- } \\
\text { bingehalt } \\
\text { (Sahli) }\end{array}$ & $\begin{array}{l}\text { Serum- } \\
\text { eiweiss } \\
(\%)\end{array}$ & $\begin{array}{l}\text { Serum- } \\
\text { chlorid } \\
(\%)\end{array}$ \\
\hline Vor d. Überdruckatmen & 68 & 4,5 & 89 & 6,552 & 0,501 \\
\hline $\begin{array}{l}\text { 40 Sek. nach d. Beginn d. Über- } \\
\text { druck }\end{array}$ & 114 & 6 & 90 & & - \\
\hline $\begin{array}{l}1 \text { Min. } 40 \text { Sekunden nach dem } \\
\text { Beginn d. Überdruck }\end{array}$ & 114 & 6 & 86 & 6,440 & 0,518 \\
\hline $\begin{array}{l}4 \text { Min. } 25 \text { Sekunden nach dem } \\
\text { Beginn d. Überdruck }\end{array}$ & 104 & $3,5-3,0$ & 77 & 6,120 & 0,548 \\
\hline $\begin{array}{l}30 \text { Sek. nach dem Schluss des } \\
\text { Überdruck }\end{array}$ & 102 & 8 & 82 & - & - \\
\hline $\begin{array}{l}40 \text { Min. nach dem Schluss des } \\
\text { Überdruckes }\end{array}$ & 74 & 4,5 & 85 & 6,440 & 0,518 \\
\hline
\end{tabular}

6. Genau wie bei Menschen verschwindet die Blutveränderung mit dem Aufhören des Überdruckes, und der alte Zustand wird allmählich wiederhergestellt. Was die Schnelligkeit der Herstellung betrifft, so ist sie je nach der Tiergattung verschieden ; bei Hunden ist sie schneller, meistens ist bei ihnen alles innerhalb von 2-3 Minuten wieder in Ordnung.

7. Bei Kaninchen geschieht es ziemlich selten, dass die Herstellung so schnell erfolgt. In den meisten Fällen ist sie sogar nach 2-3 Minuten noch garnicht $\mathrm{zu}$ erkennen oder nur sehr gering. Für die vollständige Herstellung scheinen mindstens über 5 Minuten nötig zu sein.

8. Als ich jene Verïnderung beim Sauerstoff- und Luftüberdruck vergleichend beobachtete, bekam ich folgendes Resultat : bei beiden Druckarten zeigte sich die Verdünnungserscheinung in den ersten paar Minuten nach dem Versuch im ganzen gleichmässig, aber bei ersterer Art wurde sie mit der Zeit immer stärker.

Versuch 3. Hund Nr. 3, o, schwarz, 20,1 kg. Ohne Narkose. 25. Januar 1925, Zimmertemperatur $18^{\circ} \mathrm{C}$. Luftüberdruck $16-18 \mathrm{~cm}$ (Wasser), 15 Minuten lang. Blutentnahme aus Kapillaren.

\begin{tabular}{|c|c|c|c|c|}
\hline Zeit & $\begin{array}{l}\text { Zahl d. rot. } \\
\text { Blutkörp. }\end{array}$ & $\begin{array}{c}\text { Hïmoglobin- } \\
\text { gehalt }\end{array}$ & $\begin{array}{c}\text { Serumeiweiss } \\
(\%)\end{array}$ & $\underset{(\%)}{\text { Serumchlorid }}$ \\
\hline $0^{\circ} \quad 5^{\prime}$ a.m. & $8,230,000$ & 96 (Sahli) & 8,260 & 0,504 \\
\hline$" 15$ & Beginn des $\dot{\mathrm{U}}$ & ruckatmens. & & \\
\hline$" 30$ & $\begin{array}{r}7,660,000 \\
7,050,000 \\
\end{array}$ & & $\begin{array}{l}7,900 \\
7,842\end{array}$ & $\begin{array}{l}0,094 \\
0,564\end{array}$ \\
\hline 10 $\begin{array}{c}40 \\
5\end{array}$ & $\begin{array}{c}\text { Sehluss des U } \\
7,960,000 \\
7,900,000\end{array}$ & $\begin{array}{r}\text { ruckat } \\
94 \\
93\end{array}$ & $\begin{array}{l}8,602 \\
8,494\end{array}$ & $\begin{array}{l}0,667 \\
0,568\end{array}$ \\
\hline
\end{tabular}


Versuch 4. Hund Nr. 3, (derselbe bei Versuch 3, nach zwei Halbstunden). Ohne Narkose. Sauerstoffiiberdruck 16-18 cm (Wasser), 17 Minuten lang. Kapillarblut.

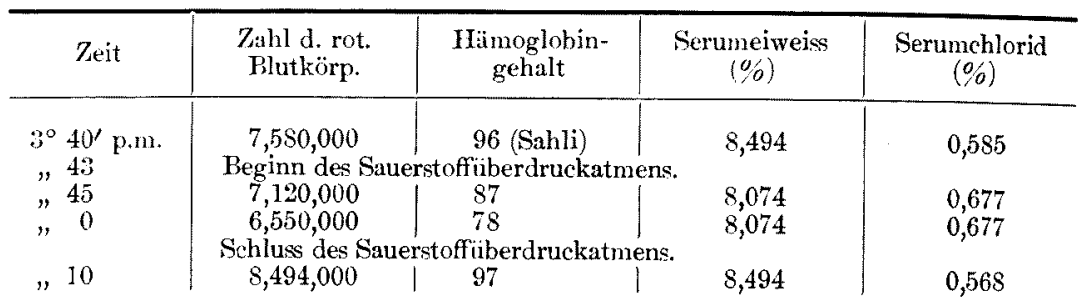

9. Die Verdünnungserscheinung des Blutes ist beim arteriellen, venösen sowie Kapillar-Blut gleich bemerkbar.

\section{B. Veränderung der Atmungskurve beim Überdruckatmen.}

Bei der Betrachtung dieser Erscheinung sind folgende zwei Punkte am wichtigsten: 1. Die Atemzahl (oder Atemphase); 2. Die Atemtiefe (oder Amplitude des Atemdruckes). Weil bei mir die Feststellung der Kurve der Trachealatmung, d. h. des Atemdruckes, die Hauptsache war, konnte ich erstere auf dem Weg der Kurvenanalyse statistisch erkennen, aber bei der Feststellung der letzteren musste ich dem Umstand Rechnung tragen, dass die Kurvenhöhe, m. a. W., die Distanz zwischen der Spitze der aufsteigenden und der Basis der absteigenden Schenkel nicht für alle Fälle die echte Tiefe der Atmung darstellt. Der Grund dafür liegt darin, dass beim Uberdruckatmen, verglichen mit der atmosphären Atmung, selbst das Experium positiven Druck zeigt, infolgedessen die Höhe herabgedrückt und niedriger, als sie wirklich ist, erscheinen lüsst.

Um ein extremes Beispiel zu nehmen : beim Wasserdruck von $30 \mathrm{~cm}$ (Hunden), $35 \mathrm{~cm}$ (Kaninchen) wurden die Bewegungen sowohl der auf-als auch der absteigenden Schenkel so gering, dass die Kurve in die Horizontallinie überging. Das hat dann der Form nach den Anschein der „Apnö̈", aber in Wirklichkeit führte das Tier starke Abdominalatmung aus. Man kann also sagen, dass je stärker der Überdruck, desto grösser die Höhe der gauzen Kurven, und dass besonders auch der Stand des Tals (beim Experium) davon beeinflusst werden muss.

In den meisten Fällen spürte das betreffende Tier unter $20 \mathrm{~cm}$ Wasser gar kein Unbehagen, machte auch keine forcierte Atmung, ja tat vielmehr sehr ruhige Atemzüge und war sogar fähig, nach seinem Belieben Druckveränderungen zu machen. Man kann also ruhig die Höhe der Kurve als 
Tiefe der Atmung betrachten, denn es heisst in der Literatur (14) :

„Der Luftwechsel in der Lunge ist Folge der Druckdifferenz der Luft innerhalb und ausserhalb der Lunge."

Von diesem Standpunkt aus analysierte ich die sich aus meinen Versuchen ergebenden Atmungskurven und gelangte zu folgenden Ergebnissen: 1. Wenn man bei Hunden schnell Uberdruckatmen ausführen lässt, wird der Atemtypus auf zweierlei Weise veründert :

(A) Abnahme der Atemzahl (Verlängerung der Phase) und der Atmungstiefe (Verkürzung der Amplitude) findet zu grleicher Zeit statt (Figg. 1 bis 5).

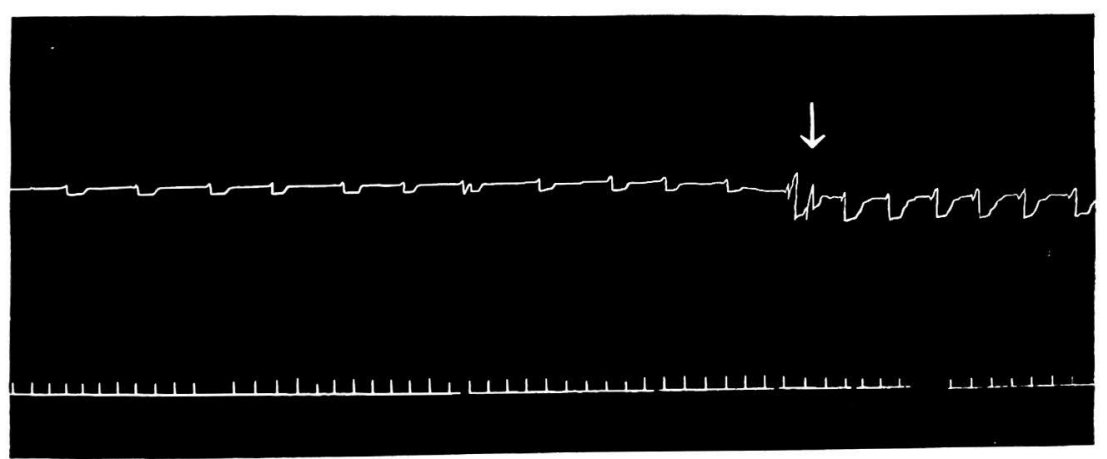

Fig. 1. Hund Nr. 10, ㅇ, rötlich-bräunlich, 12,0 kg. 21. Februar 1925 (Versuch 8). Kurve der Überdruckatmung (von rechts nach links zu lesen; aufsteigende Schenkel : Experium, absteigende Schenkel : Insperium). Pfeil : Beginn d. Überdruckatmung. Zeitmark in 1 Sekunde.

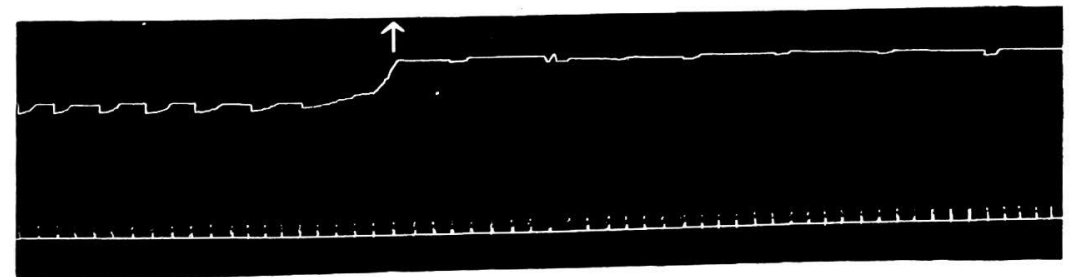

Fig. 2. Hund Nr. 11, 予, rötlich-brüunlich, 12,13 kg. 5. MIärz 1925 (Versuch 9). Kurve d. Überdruckatmung (Anfangszeit ausgelassen). Pfeil : Schluss d. Überdruckatmung. Zeitmark in 2 Sekunden. 


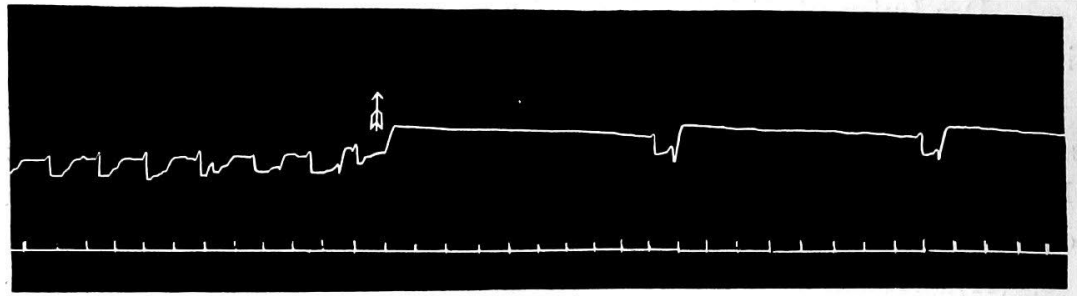

Fig. 3. Hund Nr. 12, 千, 12,8 kg. 7. M̈̈rz 1925 (Versuch 11). Kurve d. Überdruckatmung (Atmung am Ende und direkt nach d. Schluss des Überdruckes). Pfeil Schluss des Überdruckes. Zeitmark in 2 Sekunden.

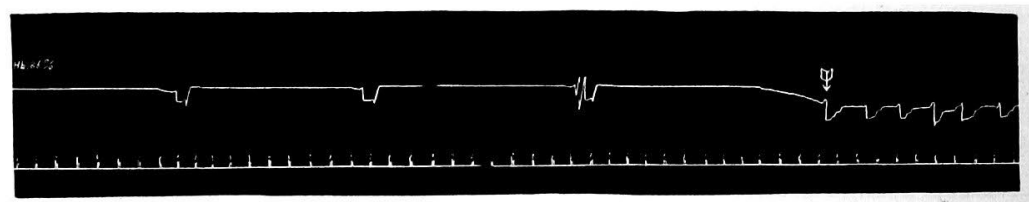

Fig. 4. Hund Nr. 12 (derselbe wie bei Fig. 3). 7. Mürz 1925 (Versuch 12). Kurve d. Überdruckatmung (Anfangszeit). Pfeil : Beginn des Überdruckes. Zeitmark in 2 Sekunden.

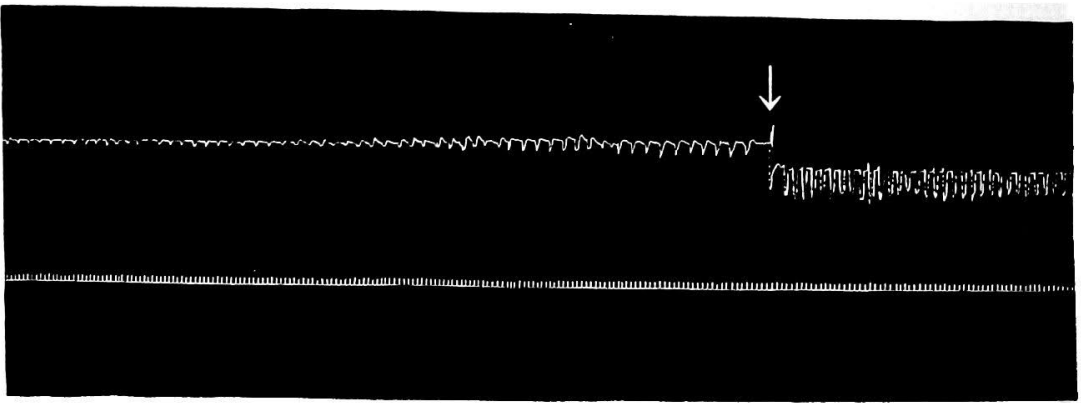

Fig. 5. Hund Nr. 22, $\odot$, schwarz und weiss gefleckt, 14,9 kg. 2. September 1925 (Versuch 21). Luftuiberdruck $35 \mathrm{~cm}$ (Wasser), 33 Minuten lang. Kurve d. Überdruckatmung (vor und direkt nach d. Beginn des Überdruckes). Pfeil : Beginn d. Überdruckatmung. Zeitmark in 2 Sekunden.

(B) Die Tiefe der Atmung vermindert sich bedeutend, während ihre Zahl die alte bleibt (Figg. 6 bis 8 ). 


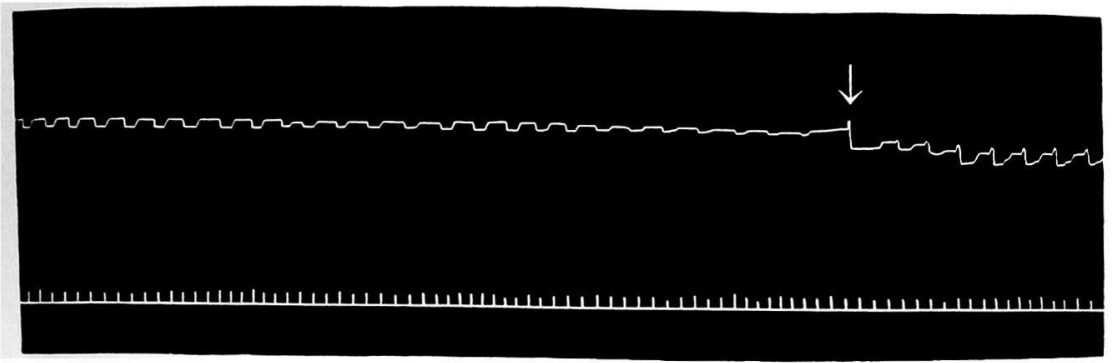

Fig. 6. Hund Nr. 16, ค, bräunlich, $8,25 \mathrm{~kg}$. 9. Juli 1925, Zinmertemperatur $24^{\circ} \mathrm{C}$. Luftüberdruck $16 \mathrm{~cm}$ (Wasser). Pfeil : Beginn d. Uberdruckatmung. Zeitmark in 2 Sekunden.

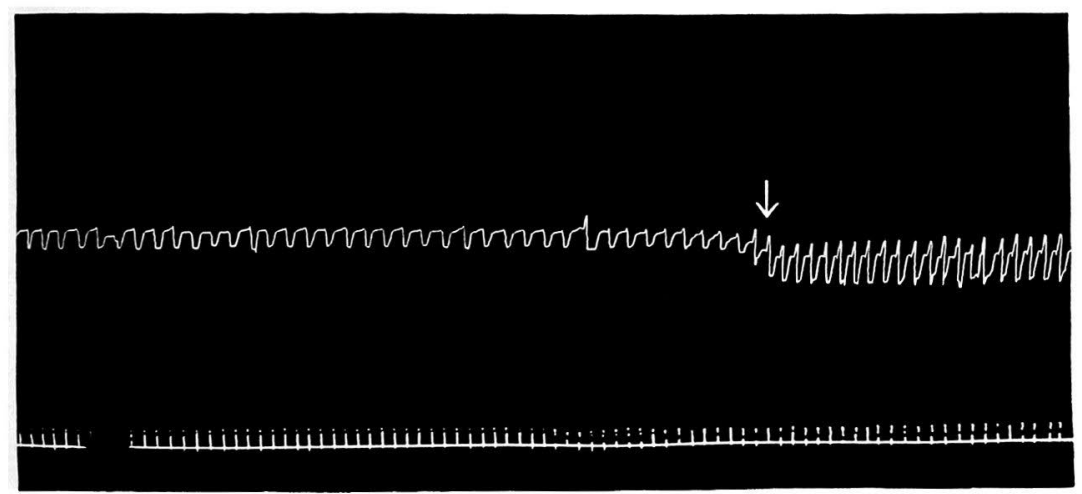

Fig. 7. Hund Nr. 17, ô, schwärzlich-brïunlich, 9,3 kg. 11. Juli 1925, Zimmertemperatur $21^{\circ} \mathrm{C}$. Kurve d. Überdruckatmung (ror und nach d. Überdruck). Pfeil : Beginn des Überdruckes. Zeitmark in 2 Sekunden.

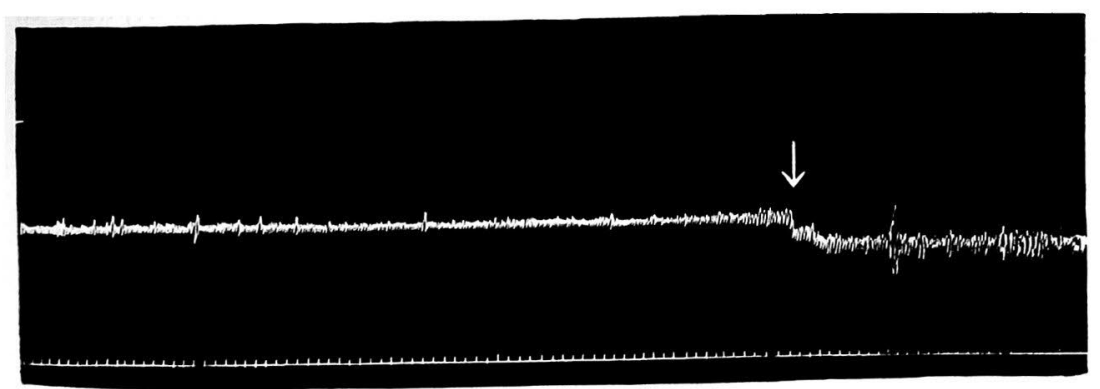

Fig. S. Hund Nr. 20, 5 , schwarz, 1,14 kg. 26. August 1925, Zimmertemperatur $26^{\circ} \mathrm{C}$. Luftiberdruck $13 \mathrm{~cm}$ (Wasser), 8 Minuten lang. Kurve d. Ziberdruckatmung. Pfeil : Beginn des Überdruckes. Zeitmark in 2 Sekunden. 
Woher die Verschiedenheit der zwei Typen kommt, das sei hier besonders bemerkt: alle Versuche 1-12 sind in den kalten Monaten, vom Januar bis März, unternommen, dagegen die Versuche von 13 ab in den wïrmeren nämlich von Ende Juni bis Mitte September. Dieses Verhältnis zeigt die folgende Tafel :

\begin{tabular}{|c|c|c|c|c|c|}
\hline Versuch & Datum & $\begin{array}{c}\text { Zimmer- } \\
\text { temperatur } \\
\left({ }^{\circ} \mathrm{C}\right)\end{array}$ & $\begin{array}{c}\text { Überdruck } \\
\text { cm } \\
\text { (Wasser) }\end{array}$ & Atemzahl & Atemtiefe \\
\hline $\begin{array}{r}2 \\
8 \\
9 \\
10 \\
11 \\
12 \\
13\end{array}$ & $\begin{array}{l}\text { 17. Januàr } \\
\text { 21. Februar } \\
\text { 5. Mürz } \\
\text { 7. Mürz } \\
\text { 7. Mürz } \\
\text { 7. Mürz } \\
\text { 29. Juni }\end{array}$ & $\begin{array}{l}17 \\
18 \\
20 \\
20 \\
15 \\
15 \\
23\end{array}$ & $\begin{array}{l}22 \\
18 \\
45 \\
45 \\
35 \\
35 \\
20\end{array}$ & $\begin{array}{c}\text { vermindert } \\
\text { ", } \\
", \\
", \\
\text { ein wenig } \\
\text { vermindert }\end{array}$ & $\begin{array}{c}\text { vermindert } \\
\text { " } \\
" \\
" \\
"\end{array}$ \\
\hline
\end{tabular}

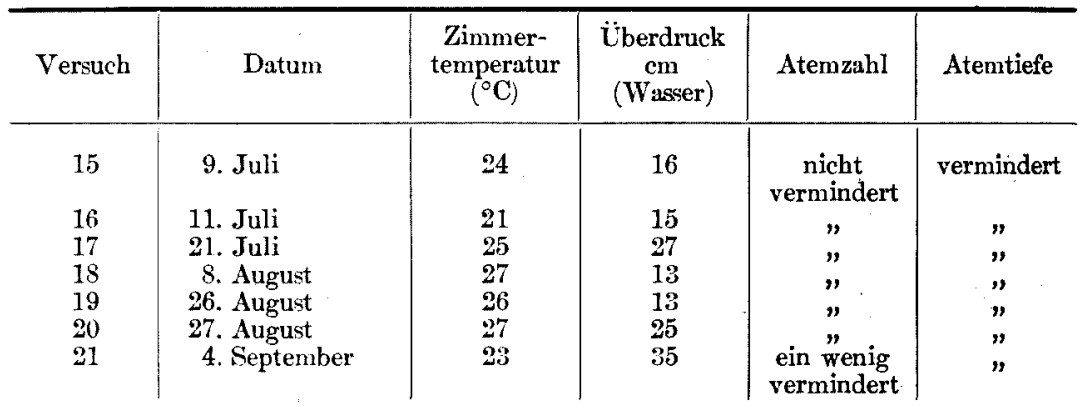

Ein Blick auf die Tafel genügt, um zu sehen, dass die Verminderung der Atemzahl nur bei warmer 'T'emperatur, nämlich im VII. und VIII. Monat nicht stattfindet. Ausser den in der Tafel angegebenen Fällen hatte ich speziell für die Atemzahl $20 \mathrm{mal}$ die Experimente wiederholt, aber es gelang mir nicht einmal, die Verminderung der Atemzahl (Verlängerung der Phase) zu beobachten. Jedermann weiss, dass Hunde in der Sommerhitze an frequenter Atmung leiden. Ob der eigenartige Atmungstypus des Hundes beim Überdruckatmen nur im Sommer einen Unterschied erfährt, wäre eine sehr interessante Frage zum vergleichenden Studium (auf welche ich spïter wieder zurückkommen will).

2. Dieser Typus kommt im erregten Zustand des Tieres gar nicht zum Vorschein, im Gegenteil sind dann Zunahme und atypische Vergrösserung der Tiefe erkennbar (Fig. 8).

3. Einige Miunten nach dem Aufhören des Uberdruckes wird der normale Atmungstypus wieder hergestellte (Figg. 2 u. 7). 
4. Die Überdrucksatmungskurve der Kaninchen hat grosse $\ddot{A} h n l i c h-$ keit mit der der Hunde im Sommer. In den meisten Fällen nämlich vermindert sich nur die Atmungstiefe, aber nicht die Atmungszahl (Figg. 9, 10 u. 11). Eine Ausnahme bei Kaninchen ist Nr. 14, wobei die Atmungszahl sich vermindert (Fig. 12).

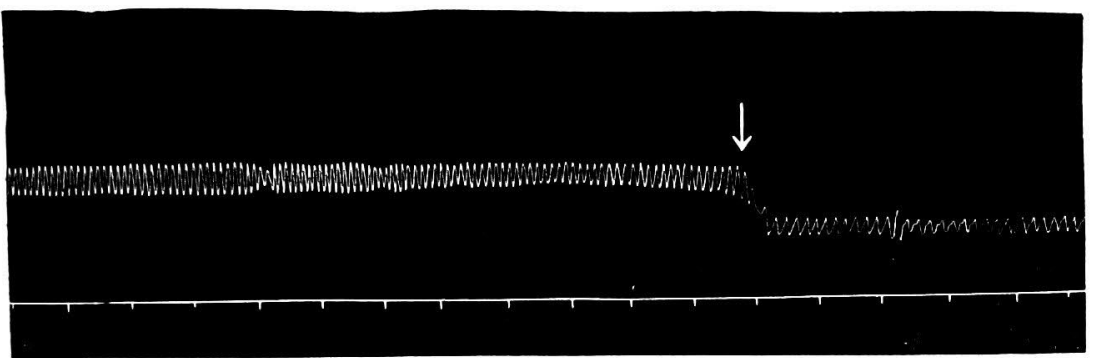

Fig. 9. Kaninchen Nr. 12, ô, $2135 \mathrm{~g}$ (Versuch 28). 16. Februar 1925, Zimmertemperatur $20^{\circ} \mathrm{C}$. Luftüberdruck $20 \mathrm{~cm}$ (Wasser). Pfeil: Beginn d. Überdruckatmung. Zeitmarke in 5 Sekunden.

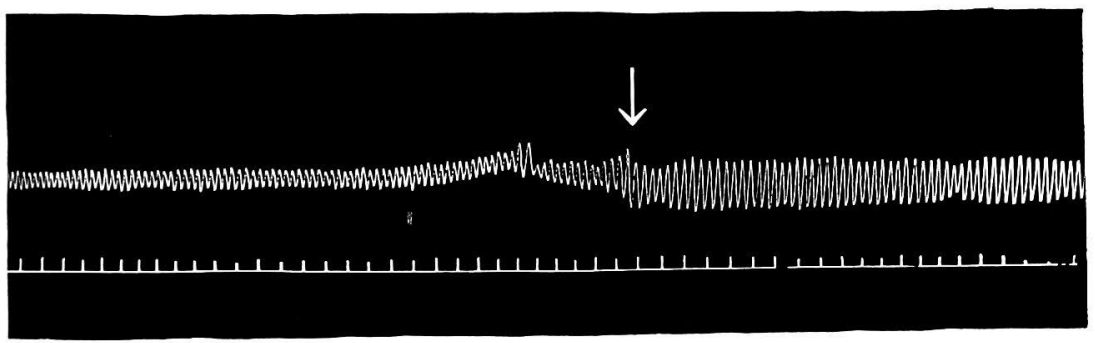

Fig. 10. Kaninchen Nr. 16, \&, 2754 g. 28. Juni 1925, Zimmertemperatur $24^{\circ} \mathrm{C}$. Sauerstoffuiberdruck $7 \mathrm{~cm}$ (Wasser), 15 Minuten lang. Pfeil: Beginn des Überdruckes. Zeitmarke in $\mathbf{2}$ Sekunden.

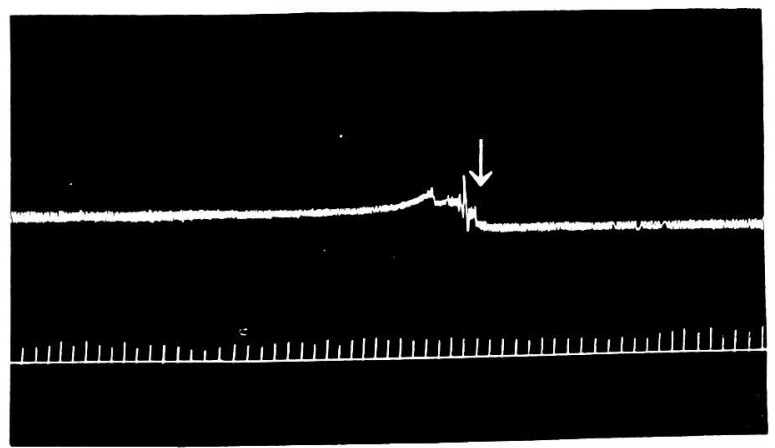

Fig. 11. Kaninchen Nr. 17, O, 2480 g. 28. Juni 1925 , Zimmertemperatur $24^{\circ} \mathrm{C}$. Luftüberdruck $7 \mathrm{~cm}$ (Wasser), 12 Minuten lang. Pfeil : Peginn des Z̈berdruckes. Zeitmark in 2 Sekunden. 


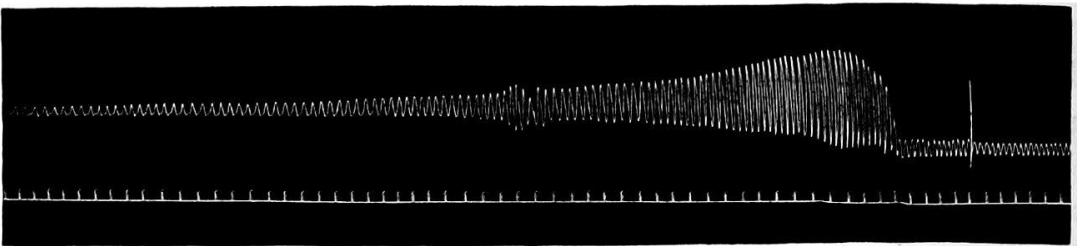

Fig. 12. Kaninchen Nr. 14, ㅇ, 1900 g. 24. Februar 1925, Zimmertemperatur $18^{\circ} \mathrm{C}$. Luftüberdruck $20 \mathrm{~cm}$ (Wasser), 6 Minuten lang (Versuch 29). Pfeil : Beginn des Überdruckes. Zeitmark in 2 Sekunden.

5. Auch ein Unterschied besteht darin, dass bei Kaninchen im Gegensatz zu Hunden die Atmungszahl keine Verminđerung, sondern Zunahme erfährt.

6. Ein anderer Unterschied ist, dass bei Kaninchen im Anfang des Überdruckes die Zunahme der Atmungstiefe, d. h. ein der tiefen Atmung ähnlicher Typus zum Vorschein kommt (Fig. 12). Diese Erscheinung kann man einfuch als nervösen Einfluss trachten.

Bei Kaninchen wird der Atmungstypus vom Klima gar nicht beeinflusst,

\section{Verhältnis von Atmungstypus und Blutkon- zentration beim Überdruckatmen.}

1. Bei Hunden tritt Blutverdünnung schon ganz kurze Zeit nach dem Uberdruckatmen ein, und wenn dieser Zustand während der Atmung fortdauert, zeigt, auch die Atmungskurve in ebenso kurzer Zeit typische Veränderung (Versuche 8 u. 9, Fig. 1) :

Versuch S. Hund Nr. 10, 开, rötlich-bräunllch, 12,0 kg. Ohne Narkose. 21. Februar 1925, Zimmertemperatur $18^{\circ} \mathrm{C}$. Luftüberdruck $20-18 \mathrm{~cm}$ (Wasser), 6 Minuten lang. In diesem Versuch wurde die Atemkurve registriert, und daraus Atemzahl und Atemtiefe analysiert. Blutentnahme aus Ohrvene. (Fig. 1.)

\begin{tabular}{|c|c|c|c|c|c|}
\hline Zeit & $\begin{array}{l}\text { Hümoglo- } \\
\text { bingehalt }\end{array}$ & $\begin{array}{l}\text { Serum- } \\
\text { eiveiss } \\
(\%)\end{array}$ & $\begin{array}{l}\text { Serum- } \\
\text { chlorid } \\
(\%)\end{array}$ & $\begin{array}{l}\text { Atemzahl } \\
\text { per } \\
\text { Minuten }\end{array}$ & $\begin{array}{l}\text { Atemtiefe } \\
(\mathrm{mm})\end{array}$ \\
\hline Vor d. Überdruckatmen & 98 (Sahli) & 6,552 & 0,528 & 12 & 7 \\
\hline $\begin{array}{l}\text { 1-2 Minuten nach d. Beginn d. } \\
\text { Überdruckatmen }\end{array}$ & & 6,332 & 0,552 & 8 & 3 \\
\hline 3 Minuten nach $\mathrm{d}$. Beginn $\mathrm{d}$. & 94 & 一 & - & 8 & 3 \\
\hline Ende d. Uberdruckatmens & 94 & 6,332 & 0,541 & 8 & 3 \\
\hline $\begin{array}{l}\text { 1,5 Minuten nach d. Schluss } \\
\text { des Überdruckatmens }\end{array}$ & 95 & 6,332 & 0,523 & 11 & 7 \\
\hline $\begin{array}{l}\text { 3,5 Minuten nach d. Schluss } \\
\text { des Überdruckatmens }\end{array}$ & 97 & 6,552 & 0,535 & 12 & 7 \\
\hline $\begin{array}{l}1 \text { Stunde nach d. Schluss des } \\
\text { Überdruckatmens }\end{array}$ & 100 & 6,552 & 0,517 & 12 & 7 \\
\hline
\end{tabular}


2. In Fall, wo bei einem mehr oder weniger erregten Hunde die Atmungszahl von vornherein etwas grösser ist, wo sich nämlich keine typische Kurve zeigt, oder wo der Überdruck nicht plötzlich, sondern ganz allmählich steigt, tritt deutliche Veränderung der Blutbestandteile erst dann ein, wenn die Überdruckatmungskurve die Atmungszahl oder die 'Tiefe zu vermindern anfängt (Fig. 13, Versuch 11):

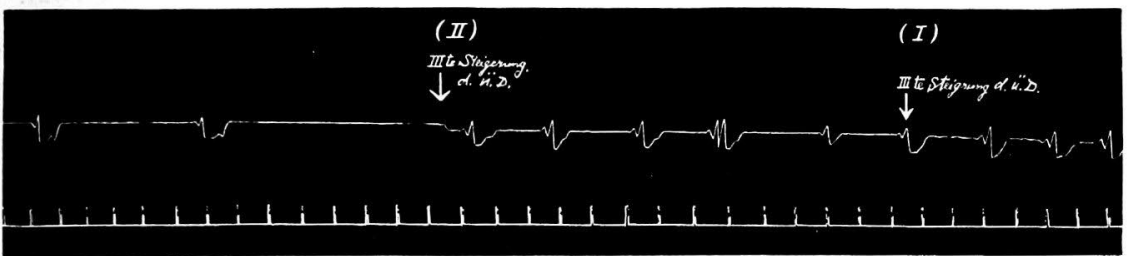

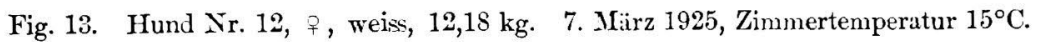
Allnühliche Steigerung des Luftüberdruckes bis $35 \mathrm{~cm}$ (Wasser) in 14 Minuten (Versuch 11). Kurve: Anfangszeit. Pfeil I: 2te Steigerung des Druckes. Pfeil II : 3te Steigerung des Druckes. Zeitmark in 2 Sekunden.

Versuche 11 und 12. Hund Nr. 12, ๆ, weiss, 12,S kg. Morphin-Narkose. 7. März 1925, Zimmertemperatur $15^{\circ} \mathrm{C}$. Allmähliche (mit Interval von 1 oder 2 Minuten) Steigerung des Luftuiberdruckes bis $35 \mathrm{~cm}$ (Wasser) in 14 Minuten. (Versuch 11 Figg. $3 \mathrm{u}$. 13).

Nach Pause von 20 Minuteu plötzliche Steigerung des Druckes bis $85 \mathrm{~cm}$ (Wasser) (Versuch 12, Fig. 4). Blutentnahme aus Ohrkapillaren.

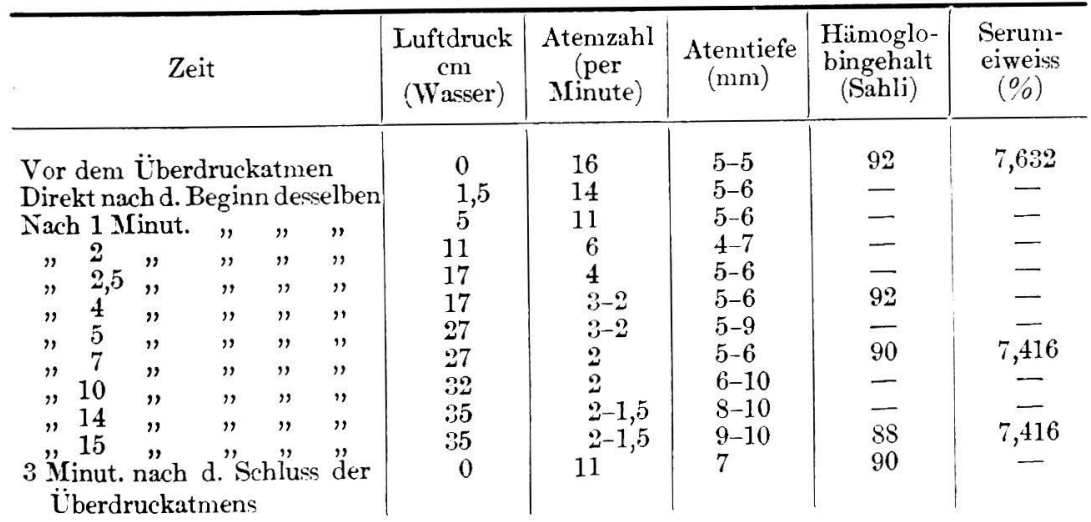

Pause von 20 Minuten.

4 Minut. nach d. Überdruckatmen

2 Minut. nach Schluss des ïberdruckatmens

35

0
$6-7$

6
86

90 
3. Im Fall, wo dic Überdruckatmungskurve in Atmungszahl und Tiefe gar keine Ver̈̈nderung zeigt, d. h. beide dieselben sind wie vor dem Überdruckatmen, bleibt auch die Blutkonzentration ohne Verïnderung oder tritt nur in ganz geringem Grade auf.

4. Hingegen bemerkt man im Fall, wo die Atemnot durch Überdruckatmen hervorgerufen wird, Blutverdickung (Fig. 8) :

Versuch 17. Hund Nr. 18, 3, schwarz, 11,4 kg. Morphin-Urethan-Narkose. 21. Juli 1925 , Zimmertemperatur $25^{\circ} \mathrm{C}$. Luftüberdruck $27 \mathrm{~cm}$ (Wasser). Blutentnahme aus Ohrkapillaren.

Der Hund war von Anfung an sehr unruhig, schon bei kleinem Reiz iusserst erregbar, und es war sogar durch Narkose ummöglich, ihn zur ruhigen Atmung zu bringen. Im Verlauf der Uberdruckatmung kam bisweilen, wenn auch ubergehend, dyspnoische Atmung vor. Es ist höchstwahrscheinlich anzunehmen, dass diese Unruhe durch das heisse Klima verursacht wurde. Wenn auch dieser Versuch in Bezug auf Atmung scheinbar nicht für unsere Untersuchungsziele geeingnet, schloss ich doch aus den Resultaten der Blutbestandteile, dass zwischen Blutzusammensetzung und Atemtypus ein gewissermassen inniger Zusammenbang bestanden habe, wie unten :

Vor der 1 berdruckatmung : Atemzahl 33 bis 35, voribergehend noch frequenter, sogar seicht eingeatmet, wobei Hämoglobingehalt 78 (Sahli) und Serumeiweiss $6,228 \%$ betrug.

Direkt nach Lberdruckatmung: Atmung ganz frequent, weshalb man durch Analyse der Kurve ihre Zahl nicht berechnen konnte. Ca. 1 Minute später wurde allmälich die Amplitude der Atmung rergrössert, dazwischen aber ganz vorübergehende dyspnoische tiefe Atmung bewerkt.

¿ Minuten spiter: Atemtiefe immer vergrössert bis zur gleichgradigen Höhe vor der Überdruckatmung. Hämoglobingehalt 75, Serumeiweiss 6,12\%.

3 Minuten spïter : plötzlich stellte sich dyspnoische Atmung ein und die auf- und absteigenden Schenkel der Atenkurve wurden ganz unregelmüssig.

5 Minuten später: Ḧ̈noglobingehalt 81 , Serumeiweiss 6,336\%.

5 Minuten nach dem Schluss des Überdruckatmens: Hämoglobingehalt 82, Serumeiweiss $6,336 \%$.

Es war bemerkennswert, dass die im Anfangsstadium in Betracht kommende Verminderung ron H:imoglobingehalt und Serumeiweiss nach dem Auftreten ron Dyspnoe schon verschwand, sogar eher Zunahme derselben stattfand.

5. Bei Kaninchen, bei denen im Anfang des Überdruckatmens Zunahme der Atmungstiefe, d. h. 'Tiefatmung, stattfindet, kommt Blutverdünnung erst mit der Verminderung derselben wie bei Hunden zum Vorschein (Fjg. 12) :

Versuch 29. Kaninchen Nr. 14, ㅇ, $1900 \mathrm{~g}$. Ohne Narkose. 24. Februar 1925, Zimmertemperature $18^{\circ} \mathrm{C}$. Luftiiberdruck $20 \mathrm{~cm}$ (Wasser), 6 Minuten lang. Blutentnahme aus Kapillaren. (Fig. 12).

\begin{tabular}{|c|c|c|c|c|c|}
\hline Zeit & $\begin{array}{c}\text { Atemzahl } \\
\text { (per } \\
\text { Minute) }\end{array}$ & $\begin{array}{l}\text { Atemtiefe } \\
(\mathrm{mm})\end{array}$ & $\begin{array}{l}\text { Hümoglo- } \\
\text { bingehalt } \\
\text { (Sahli) }\end{array}$ & $\begin{array}{l}\text { Serum- } \\
\text { eiweiss } \\
(\%)\end{array}$ & $\begin{array}{l}\text { Serun- } \\
\text { chlorid } \\
(\%)\end{array}$ \\
\hline $\begin{array}{l}\text { Vor d. Uberdruck } \\
\text { Direkt nach d. Beginn desselben }\end{array}$ & $\begin{array}{l}54 \\
60\end{array}$ & $\begin{array}{c}6 \\
38-27\end{array}$ & 86 & 7,200 & $\stackrel{0,718}{-}$ \\
\hline
\end{tabular}




\begin{tabular}{|c|c|c|c|c|c|}
\hline Zeit & $\begin{array}{c}\text { Atemzahl } \\
\text { (per } \\
\text { Minute) }\end{array}$ & $\begin{array}{l}\text { Atemtiefe } \\
(\mathrm{mm})\end{array}$ & $\begin{array}{l}\text { Hïmoglo- } \\
\text { bingehalt } \\
\text { (Sahli) }\end{array}$ & $\begin{array}{c}\text { Serum- } \\
\text { eiveiss } \\
(0,0)\end{array}$ & $\begin{array}{l}\text { Serunt- } \\
\text { chlorid } \\
(0,0)\end{array}$ \\
\hline 1 Min. spïter & 44 & $12-7$ & $\$ 9$ & - & - \\
\hline $2 "$, & 30 & 4 & 76 & - & - \\
\hline $4 "$ & 32 & 5 & 73 & 6,768 & 0,736 \\
\hline $\begin{array}{l}\text { Direkt nach dem Schluss des } \\
\text { Überdrcukatmens }\end{array}$ & 48 & 2 & - & - & - \\
\hline 1 Min. später & 44 & $6-8$ & 78 & - & - \\
\hline $2, \quad "$ & 52 & 12 & 一 & - & - \\
\hline $4 "$, & $4 \mathrm{~S}$ & 10 & 89 & - & - \\
\hline $6 ", "$ & 46 & 7 & 91 & 7,092 & 0,736 \\
\hline
\end{tabular}

6. Auch bei denjenigen Kaninchen, die wie Hunde von vornherein die typische Kurve zeigen, ist die Veründerung des Blutes demgemäss gross und schnell (Versuch 36, Fig. 14). Dabei sei bemerkt, dass dies bei Kaninchen nicht immer zutrifft und die meistens den unter 5 angegebenen Typus zeigen.

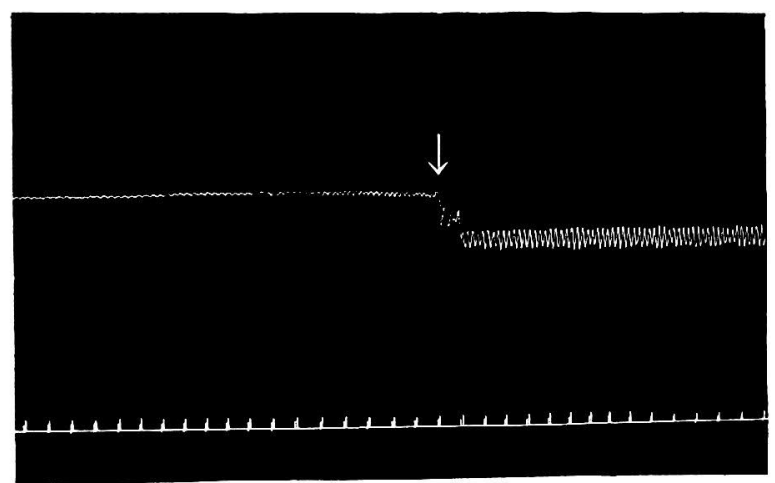

Fig. 14. Kaninchen Nr. 20, 宅, 2040 g. 2. September 1925 , Zimmertemperatur $27^{\circ} \mathrm{C}$. Luftüberdruck $25 \mathrm{~cm}$ (Wasser), 15 Minuten lang. Kurve: vor und direkt nach d. Beginn des Üherdruckes (Versuch 36). Pfeil : Beginn des Druckes. Zeitmark in 2 Sekunden.

Versuch 86. Kaninchen Nr.20, 3, 2040 g. Ohne Narkose. 2. September 1925, Zimmertemperatur $27^{\circ} \mathrm{C}$. Luftüberdruck $25 \mathrm{~cm}$ (Wasser), 15 Minuten lang. (Fig. 14).

\begin{tabular}{|c|c|c|c|c|c|c|}
\hline Zeit & Bedingung & $\begin{array}{l}\text { Atemzahl } \\
\text { (per } \\
\text { Minute) }\end{array}$ & $\begin{array}{l}\text { Atemtiefe } \\
(\mathrm{mm})\end{array}$ & $\begin{array}{l}\text { Hämoglo- } \\
\text { bingehalt } \\
\text { (Sahli) }\end{array}$ & $\begin{array}{l}\text { Serum- } \\
\text { eiweiss } \\
(0)\end{array}$ & $\begin{array}{l}\text { Serum- } \\
\text { chlorid } \\
(0.0)\end{array}$ \\
\hline $\begin{array}{l}10^{\circ} 40^{\prime} \\
1050\end{array}$ & $\begin{array}{l}\text { Keine Maske } \\
5 \text { Min. nach Anwen- } \\
\text { dung der Maske }\end{array}$ & $\begin{array}{l}108 \\
120\end{array}$ & $\overrightarrow{4}$ & $\begin{array}{l}80 \\
80\end{array}$ & $\overline{6, \overline{s i 6}}$ & $\begin{array}{l}0,602 \\
0,689\end{array}$ \\
\hline $10 \quad 55$ & $\begin{array}{l}\text { Beginn des Über- } \\
\text { druckatmens }\end{array}$ & & & & & \\
\hline
\end{tabular}




\begin{tabular}{|c|c|c|c|c|c|c|}
\hline Zeit & Bedingung & $\begin{array}{c}\text { Atemzahl } \\
\text { (per } \\
\text { Min.) }\end{array}$ & $\begin{array}{l}\text { Atemtiefe } \\
(\mathrm{mm})\end{array}$ & $\begin{array}{c}\text { Hümoglo- } \\
\text { bingehalt } \\
\text { (Sahli) }\end{array}$ & $\begin{array}{l}\text { Serum- } \\
\text { eiweiss } \\
(\%)\end{array}$ & $\begin{array}{c}\text { Serum- } \\
\text { chlorid } \\
(\%)\end{array}$ \\
\hline $10^{\circ} 56^{\prime}$ & $\begin{array}{l}1 \text { Min. nach d. Über- } \\
\text { druckatmung }\end{array}$ & 110 & 0,5 & 75 & 6,536 & 0,677 \\
\hline 1058 & 3 Min. " " " & 120 & 0,5 & 73 & 一 & - \\
\hline 1110 & $\begin{array}{l}15 \text { Min. " } \\
\text { u. Schluss der Über- } \\
\text { druckatmung }\end{array}$ & 120 & 0,3 & 72 & 6,336 & 0,707 \\
\hline 1111 & $\begin{array}{l}1 \text { Min. nach Schlues d. } \\
\text { Überdrruckatmung }\end{array}$ & 108 & 3 & 80 & - & - \\
\hline 11. 15 & $\begin{array}{l}4 \text { Min. nach Entfer- } \\
\text { nung d. Maske }\end{array}$ & 120 & - & 82 & 6,752 & 0,702 \\
\hline
\end{tabular}

7. Es passiert sehr oft, dass bei Kaninchen Atmungszahl und Tiefe direkt nach dem Aufhören des Überdruckatmens noch in bedeutend gesteigertem Zustand bestehen bleiben, was von dem Verhalten bei Hunden sehr verschieden ist. Damit im Zusammenhang bleibt das Blut auch in verdünntem Zustand; erst nach 5-6 Minuten, wenn die Atmung zum alten Zustand zurückkehrt, gewinnen die Blutbestandteile ihre Konzentration von vor dem Überdruckatmen wieder.

\section{Veränderung der Konzentration des Blutes bei Unterdruckatmung.}

Der Grad der Blutverdickung beim Unterdruckatmen ist je nach den einzelnen Momenten sehr verschieden, zum Beispiel bei Hunden :

1. Im Lauf des Unterdruckatmens bleibt der Eindickungsgrad im grossen und ganzen derselbe :

Versuch 37. Hund Nr. 5, f, schwarz, 13,6 kg. Morphin-Narkose. 5. Februar 1925, Zimmertemperatur $17^{\circ} \mathrm{C}$. Unterdruck $10 \mathrm{~cm}$ (Wasser), 20 Minuten lang. Blutentnahme aus Ohrrene.

\begin{tabular}{|c|c|c|c|c|}
\hline Zeit & Pedingung & $\begin{array}{l}\text { Hïmoglo- } \\
\text { bingehalt } \\
\text { (Subli) }\end{array}$ & $\begin{array}{l}\text { Serum- } \\
\text { eiweiss } \\
(\%)\end{array}$ & $\begin{array}{l}\text { Serum- } \\
\text { chlorid } \\
(\%)\end{array}$ \\
\hline $\begin{array}{c}\text { Vor d. Lnterdruck } \\
" n\end{array}$ & $\begin{array}{l}\text { Keine Maske } \\
5 \text { Min. nach Maskenan- }\end{array}$ & $\begin{array}{l}102 \\
101\end{array}$ & $\begin{array}{l}6,336 \\
6,336\end{array}$ & $\begin{array}{l}0,550 \\
0,574\end{array}$ \\
\hline $\begin{array}{l}\text { I Min. nach d. Unter- } \\
\text { druck }\end{array}$ & " & 108 & 6,444 & 0,544 \\
\hline 10 Min. spüter & $"$ & 104 & 6,336 & 0,550 \\
\hline 20 & $"$ & 104 & 6,120 & 0,550 \\
\hline $\begin{array}{l}3 \text { Min. nach dem Schluss } \\
\text { d. Unterdruckes }\end{array}$ & $"$ & 98 & 5,902 & 0,558 \\
\hline $15 \quad " \quad " \quad$ & $\begin{array}{l}5 \text { Min. nach d. Entfer- } \\
\text { nung der Maske }\end{array}$ & 104 & 6,120 & 0,558 \\
\hline
\end{tabular}


2. Direkt nach dem Unterdruckatmen erreicht die Eindickung ihren höchsten Grad und kehrt mit der Zeit zum normalen Zustand zurück :

Versuch 38. Hund Nr. 6, t, weiss, 13,21 kg. Morphin-Narkose. 5. Februar 1925, Zimmertemperatur $16^{\circ} \mathrm{C}$. Unterdruck $18 \mathrm{~cm}$. Blutentnahme aus Arterie.

\begin{tabular}{|c|c|c|c|}
\hline Zeit & $\begin{array}{l}\text { Häimoglobin- } \\
\text { gehalt } \\
\text { (Sahli) }\end{array}$ & $\begin{array}{l}\text { Serumeiweiss } \\
(\%)\end{array}$ & $\begin{array}{c}\text { Serumchlorid } \\
(\%)\end{array}$ \\
\hline $\begin{array}{l}10 \text { Min. vor d. Unterdruck } \\
2 \text { Min. nach d. Unterdruck } \\
10 \text { Min. spüter } \\
20 \text { " " " " " } \\
2 \text { Min. nach Schluss d. Unterdrucks } \\
20 " \text { " " }\end{array}$ & $\begin{array}{l}87 \\
92 \\
93 \\
90 \\
87 \\
85\end{array}$ & $\begin{array}{l}6,752 \\
6,752 \\
6,860 \\
6,860 \\
6,536 \\
6,536\end{array}$ & $\begin{array}{l}0,581 \\
0,575 \\
0,575 \\
0,569 \\
0,576 \\
0,580\end{array}$ \\
\hline
\end{tabular}

3. Direkt nach dem Schluss von Unterdruckatmen erfährt das Blut keine Veränderung, um dann mit der Zeit Schritt für Schritt dicker zu werden :

Versuch 40. Hund Nr. 8, \}, bräunlich, 13,8 kg. Morphin-Narkose. 10. Mürz 1925, Zimmertemperatur $20^{\circ} \mathrm{C}$. Blutentnahme aus Ohrvene. Unterdruck $15 \mathrm{~cm}$ (Wasser), 20 Minuten lang.

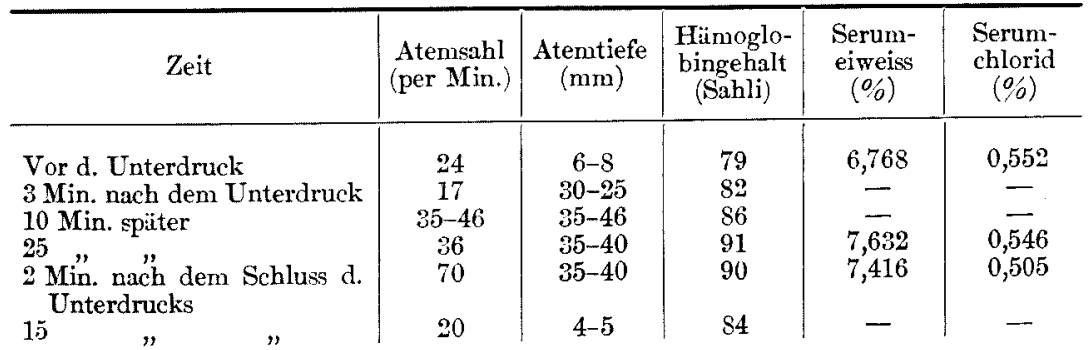

4. Im Anfang des Unterdruckatmens erreicht das Blut einmal einen gewissen Grad der Eindickung, wird dann dünner, um gegen Ende des Verfahrens wieder dicker zu werden.

5. Im ganzen Verlauf des Unterdruckatmens ändert es sich gar nicht.

Versuch 41. Hund Nr. 20, 今. schwarz, 6,57 kg. Ohne Narkose. 29. April 1925, Zimmertemperatur $23^{\circ} \mathrm{C}$. Unterdruck $15 \mathrm{~cm}$ (Wasser), 5 Minuten lang. Blutentnahme aus Ohrrene.

Vor dem Unterdruck Atemzahl 40 per Min. Atemtiefe 7-5 mm, Hümoglobingehalt 90 (Sabli) ; 5 Minuten nach der Anwendung von Unterdruck keine Ab-und Zunahme bemerkbar. Wegen ganz hochgradiger Atemnot wurde das Unterdruckverfahren sofort aufgehört. 
Direkt damach fand man wie bei Überdruckatmung mehrmalige ganz lange (Veründerung der Phase) und sehr oberflüchliche (Verkürzung der Amplitude) Atemzïge, wobei Hämoglobin. gehalt $\$ 7$ betrug.

Bei Kaninchen nimmt es nur selten den Typus von 2, aber in den meisten Fällen den Typus von 3 an, d. h. mit der Zeit allmählichen Fortschritt in der Eindickung:

Versuch 43. Kaninchen Nr. 4, ㅇ, 2509 g. Ohne Narkose. 3 Februar 1925, Zimmertemperatur $18^{\circ} \mathrm{C}$. Blutentnahme aus Ohrarterie. Unterdruck $12 \mathrm{~cm}$ (Wasser), 20 Minuten lang.

\begin{tabular}{|c|c|c|c|}
\hline Zeit & $\begin{array}{l}\text { Hämoglobin- } \\
\text { gehalt } \\
\text { (Sahli) }\end{array}$ & $\begin{array}{c}\text { Serumeiweiss } \\
(\%)\end{array}$ & $\begin{array}{c}\text { Serumchlorid } \\
(\%)\end{array}$ \\
\hline $\begin{array}{l}\text { Vor d. Unterdruck } \\
2 \text { Min. nach d. Unterdrucks } \\
20 \text { Min. später } \\
3 \text { Min. nach Schluss d. Tnterdrucks } \\
20, ", ", ", ",\end{array}$ & $\begin{array}{l}88 \\
91 \\
93 \\
84 \\
89\end{array}$ & $\begin{array}{l}5,248 \\
5,248 \\
5,357 \\
5,139 \\
5,248\end{array}$ & $\begin{array}{l}0,550 \\
0,532 \\
0,539 \\
0,573 \\
0,544\end{array}$ \\
\hline
\end{tabular}

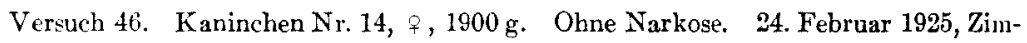
mertemperatur $17^{\circ} \mathrm{C}$. Unterdruck $20 \mathrm{~cm}$ (Wasser), 6 Minuten lang. Blutentnahme aus Ohrrene.

\begin{tabular}{|c|c|c|c|c|}
\hline Zeit & $\begin{array}{c}\text { Atemzahl } \\
\text { (per Min.) }\end{array}$ & $\begin{array}{c}\text { Hämoglo- } \\
\text { bingehalt } \\
\text { (Sahli) }\end{array}$ & $\begin{array}{l}\text { Serum- } \\
\text { eiweiss } \\
(\%)\end{array}$ & $\begin{array}{c}\text { Serum- } \\
\text { chlorid } \\
(\%)\end{array}$ \\
\hline $\begin{array}{l}\text { Vor d. Unterdruck } \\
1 \text { Min. nach d. Unterdruck } \\
2 \text { Min. } 45 \text { Sek. später } \\
2 \text { Min. } 27 \text { "' "' } \\
1 \text { Min. } 10 \text { Sek. nach Schluss d. } \\
\text { Unterdrucks } \\
3 \text { Min. spüter }\end{array}$ & $\begin{array}{l}68 \\
74 \\
56 \\
48 \\
32 \\
74\end{array}$ & $\begin{array}{l}88 \\
87 \\
88 \\
93 \\
95 \\
90\end{array}$ & $\begin{array}{l}7,200 \\
7,200 \\
7,416 \\
= \\
7,416\end{array}$ & $\begin{array}{l}0,707 \\
0,702 \\
0,719 \\
- \\
0,725\end{array}$ \\
\hline
\end{tabular}

Atemkurve. Fig. 17.

Bei der durch Aufhören des Unterdruckatmens erregten Herstellung des Normalzustandes des Blutes sind Hunde empfindlicher als Kaninchen.

\section{E. Verhältnis von Atmungstypus und Blutzusam- mensetzung beim Unterdruckatmen.}

Bei Hunden war die Kurve der Unterdruckatmung sehr unregelmässig so dass ich daraus keinen Zusammenhang derselben mit den Blutbestandteilen ausfinden konnte. 
Bei Kaninchen vermindert sich mit der bedeutenden Steigerung der Blutverdickung die Atmungstiefe (Amplitudeverminderung), d. h. ein fast gleich ruhiger Atmungszustand wie bei normaler Atmung wird wiedergewonnen. Das Fehlen der Dyspnoe kann man also einen Unterschied bei Hunden betra hten (Figg. 15 u. 16).

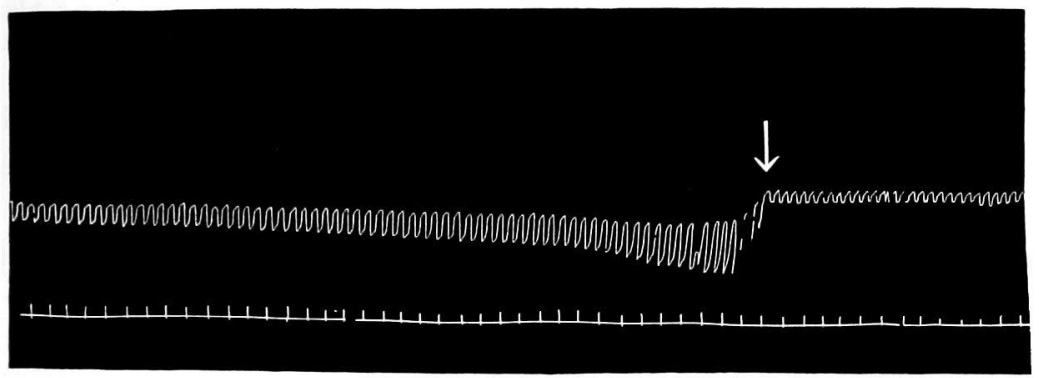

Fig. 15. Kaninchen Nr. 13, \&, 2340 g. (Versuch 45). 29. Februar 1925, Zimmertemperatur $17^{\circ} \mathrm{C}$. Unterdruck $10 \mathrm{~cm}$ (Wasser), 50 Minuten lang. Kurve: vor und direkt nach dem Beginn des Unterdruckes. Pfeil : Beginn des Unterdruckes. Zeitmark in 2 Sekunden.

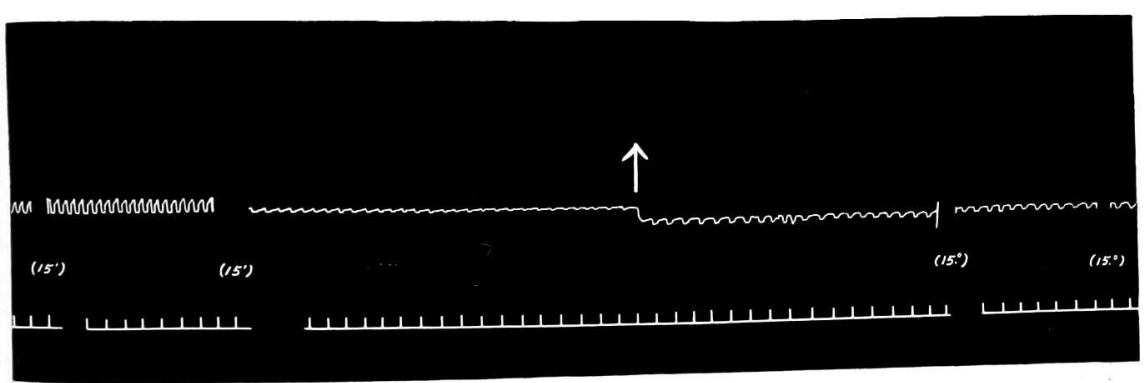

Fig. 16. Dasselbe wie bei Fig. 15. Kurve: an Ende des Unterdruckatmens, direkt und 15 Minuten nach dem Schluss des Unterdruckes. Pfeil: Schluss des Unterdruckes.

Die Atmungskurve nach Aufhören des Unterdruckatmens stellt einen sehr interessanten Typus, d. h. eine beinah geradlinige Form der Kurve dar, wobei man ganz oberflächliches und langsames Atmen beobachtet (Figg. 16 u. 17). In dieser Zeit ist das Blut noch in seinem abnormalen verdickten Zustand. 


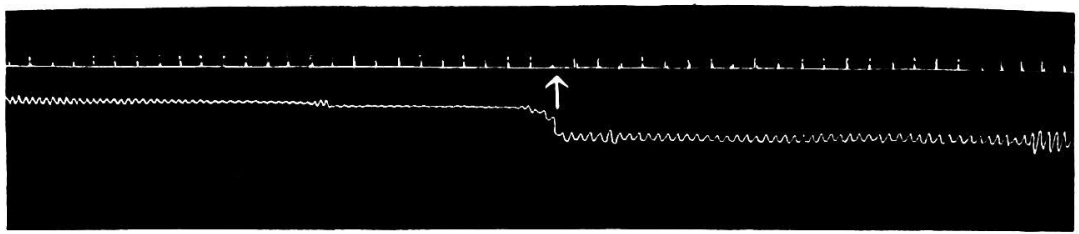

Fig. 17. Kaninchen Nr. 14, of 1900 g. 24. Februar 1925 , Zimmertemperatur $17^{\circ} \mathrm{C}$. Unterdruck $20 \mathrm{~cm}$ (Wasser), 6 Minuten lang. Kurve: am End und direkt nach dem Schluss des Unterdruckes (Versuch 46). Pfeil : Schluss des Unterdruckes. Zeitmark in 2 Sekunden.

Erst parallel mit der allmählichen Steigerung der Atmungszahl sowie der Tiefe (30 Sekunden bis 5-6 Minuten) wird das Blut dünner, bis es endlich zu seinem alten Zustand zurückkommt.

Beim Unterdruckatmen scheint das Klima bei beiden Tiergattungen keinen Einfluss auf den Atmungstypus auszuäben.

\section{F. Einflüss von Einrichtung der Experimente} und Blutentnahme selbst.

Das Sauerstoffüberdruckapparat nach 'Tiegel ist eigentlich ein Maskenapparat. Es handelte sich cleshalb bei meinen Experimenten, wieschon im 2. Kapitel erwïhnt wurde, um den Atmungszustand im Innern eines abgesperrten Raumes, was auf den Atmungstypus einigermassen von Einfluss ist.

Nach den Ergebnissen meiner Kontrollversuche ist die Verminderung der Atmungszahl bei Hunden unvermeidlich (Versuch 49 und 50), während sie bei Kaninchen sehr schwankt; bald vermindert sie sich wie bei Hunden (besonders unter Narkose: Versuch 60), bald ist keine nennenswerte Veränderung bemerkbar (Versuch 59), bald nimmt sie zu (Versuch 58).

Versuch 49. Hund Nr. 23, ô, brïunlich, 6,837 kg. Morphin-Narkose. 10. Oktober 1925, Zimmertemperatur $21^{\circ} \mathrm{C}$. Einfluss von Maskenanwendung (kein Über-oder Unterdruck). Blutentnahme aus Obrkapillaren.

\begin{tabular}{|c|c|c|c|c|c|}
\hline Zeit & $\begin{array}{c}\text { Atemzahl } \\
\text { (per Min.) }\end{array}$ & $\begin{array}{l}\text { Atemtiefe } \\
\quad(\mathrm{mm})\end{array}$ & $\begin{array}{c}\text { Hümoglo- } \\
\text { bingehalt } \\
\text { (Sahli) }\end{array}$ & $\begin{array}{l}\text { Serum- } \\
\text { eiweiss } \\
(\%)\end{array}$ & $\begin{array}{l}\text { Serun- } \\
\text { chlorid } \\
(\%)\end{array}$ \\
\hline Vor d. Anwendur & 18 & - & ss & 8,280 & 0,535 \\
\hline 5 Min. spüter & 13 & 3,5 & 88 & 8,280 & 0,546 \\
\hline $8 n$ & 13 & 3,5 & ss & 8,280 & 0,535 \\
\hline $20 \%$ & 14 & 3,5 & 87 & 8,280 & 0,552 \\
\hline
\end{tabular}

Atemzabl deutlich vermindert, Atemtiefe zeigt im Laufe der Anwendung keine nennenswerte Verïnderung. Blutbestandteile auch ohne Veränderung. Nach Entfernung der Maske erschien der Hund ermüdet. 
Versuch 50. Hund Nr. 24, 古, bräunlich, 6,77 kg. Ohne Narkose. 14. Oktober 1925, Zimmertemperatur $17^{\circ} \mathrm{C}$. Anwendung der Maske (kein Über oder Unterdruck). Blutentnahme aus Ohrvene.

\begin{tabular}{l|c|c|c|c|c}
\hline \multicolumn{1}{c|}{ Zeit } & $\begin{array}{c}\text { Atemzahl } \\
\text { (per Min.) }\end{array}$ & $\begin{array}{c}\text { Atemtiefe } \\
(\mathbf{m m})\end{array}$ & $\begin{array}{c}\text { Hïmoglo- } \\
\text { bingehalt } \\
\text { (Sahli) }\end{array}$ & $\begin{array}{c}\text { Serum- } \\
\text { eiweiss } \\
(\%)\end{array}$ & $\begin{array}{c}\text { Serum- } \\
\text { chlorid } \\
(\%)\end{array}$ \\
\hline Vor d. Anwendung & 23 & - & 107 & 7,740 & 0,556 \\
5 Min. nach Anwendung & 22 & 3 & 105 & - & - \\
9 Min. später & 20 & $2-4$ & 103 & 7,740 & 0,561 \\
$\mathbf{1 3}, "$, & 25 & 3 & 104 & - & - \\
$\mathbf{2 0} "$, & 20 & $\mathbf{2} 4$ & 103 & 7,740 & 0,566
\end{tabular}

Nur geringgradige Schwankung an $\mathrm{Zahl}$ und Tiefe der Atmung zu konstatieren, sonst keine nennenswerte Verïnderung bemerkbar.

Versuch 58. Kaninchen Nr. 21, o, $1850 \mathrm{~g}$. Ohne Narkose. 13. Oktober 1925, Zimmertemperatur $17^{\circ} \mathrm{C}$. Anwendung der Maske (kein Über- und Unterdruck), 30 Minuten lang. Blutentnahme aus Ohrvene.

\begin{tabular}{|c|c|c|c|c|c|}
\hline Zeit & $\begin{array}{r}\text { Atemzahl } \\
\text { (per Min.) }\end{array}$ & $\begin{array}{l}\text { Atemtiefe } \\
(\mathrm{mm})\end{array}$ & $\begin{array}{c}\text { Hämoglo- } \\
\text { bingehalt } \\
\text { (Sabli) }\end{array}$ & $\begin{array}{l}\text { Serum- } \\
\text { eiweiss } \\
(\%)\end{array}$ & $\begin{array}{l}\text { Serum } \\
\text { chlorid } \\
(\%) \\
\end{array}$ \\
\hline $\begin{array}{l}\text { Vor d. Anwendung } \\
3 \text { Minuten nach d. Anwendung } \\
10 \text { Minuten spïter } \\
20 \quad " \quad " \\
32\end{array}$ & $\begin{array}{l}65 \\
68 \\
70 \\
75 \\
70\end{array}$ & $\begin{array}{r}\overline{10} \\
13 \\
8 \\
12\end{array}$ & $\begin{array}{l}78 \\
76 \\
78 \\
77 \\
77\end{array}$ & $\begin{array}{l}6,120 \\
\overline{6,120} \\
\overline{6,120}\end{array}$ & $\begin{array}{l}0,551 \\
0,545 \\
- \\
0,551\end{array}$ \\
\hline
\end{tabular}

Relative grosse Vermehrung an Atemzahl, sonst waren keine nennenwerten Verïnderungen zu sehen.

Versuch 59. Kaninchen Nr. 22, q, 2700g. Ohne Narkose. 11. Oktober 1925, Zimmertemperatur $19^{\circ} \mathrm{C}$. Anwendung der Maske, Blutentnahme aus Ohrarterie.

\begin{tabular}{|c|c|c|c|c|c|}
\hline Zeit & $\begin{array}{r}\text { Atemzahl } \\
\text { (per Min.) }\end{array}$ & $\begin{array}{l}\text { Atemtiefe } \\
(\mathrm{mm})\end{array}$ & $\begin{array}{c}\text { Hïmoglo- } \\
\text { bingehalt } \\
\text { (Sahli) }\end{array}$ & $\begin{array}{l}\text { Serum- } \\
\text { eiweiss } \\
(\%)\end{array}$ & $\begin{array}{l}\text { Serum- } \\
\text { chlorid } \\
(\%)\end{array}$ \\
\hline $\begin{array}{l}\text { Vor d. Anwendung } \\
4 \text { Min. nach Anwendung } \\
10 \text { Minuten später } \\
17 \quad " \text { " " " } \\
24 \quad\end{array}$ & $\begin{array}{l}65 \\
60 \\
62 \\
62 \\
68\end{array}$ & $\begin{array}{l}- \\
5 \\
7 \\
3 \\
4\end{array}$ & $\begin{array}{l}76 \\
74 \\
74 \\
75 \\
74\end{array}$ & $\begin{array}{l}7,308 \\
7,308 \\
7,308 \\
7,200 \\
7,200\end{array}$ & $\begin{array}{l}0,552 \\
0,558 \\
0,552 \\
0,575 \\
0,564\end{array}$ \\
\hline
\end{tabular}

Mässige Verminderungen an Atemzahl und Atentiefe, aber keine Veränderung an Blutbestandteilen.

Versuch 60. Kaninchen Nr. 25, ㅇ, 2010 g. Morphin-Narkose. 20. November 1925, Zimmertemperatur $18^{\circ} \mathrm{C}$. Anwendung der Maske 25 Min. lang. Blutentnahme aus Ohrarterie.

\begin{tabular}{l|c|c|c}
\hline \multicolumn{1}{c|}{ Zeit } & $\begin{array}{c}\text { Atemzahl } \\
\text { (per Min.) }\end{array}$ & $\begin{array}{c}\text { Atemtiefe } \\
\text { (mm) }\end{array}$ & $\begin{array}{c}\text { Hämoglo- } \\
\text { bingehalt } \\
\text { (Sahli) }\end{array}$ \\
\hline Vor d. Anwendung & 42 & - & 83 \\
2 Min. nach Anwendung & 38 & 3 & 81 \\
10 Minuten später & 36 & 3 & 81 \\
$16 \quad "$ & 35 & 2 & 82 \\
25 " " & 33 & $\mathbf{2}$ & 81 \\
5 Min." nach Entfernung der Maske & 38 & - & 80
\end{tabular}


Aber im ganzen sind die Veränderungen, verglichen mit denen beim Uberdruckatmen oder bei der uns beschäftigenden Sauerstoffinhalation sehr gering, also kaum nennenswert sind. Weder in der Kurve noch mit blossem Auge ist forciertes Atmen wahrzunehmen.

Eine andere Frage ist es, ob die Einrichtung dieses Apparates selbst (im Fall, wo weder Über- noch Unterdruckatmen stattfindet) und ob die Blutentnahme, die wenn auch immer nur in kleiner Menge, so doch einigemal innerhalb 30 Minuten bis 1 Stunde ausgeführt wird, auf die Blutbestandteile Einfluss ansübt?

Aus meinen Experimenten ergab es sich, dass solche Fragen gar nicht in Betracht kommen, d. h. der befürchtete Einfluss blieb ganz aus oder war höchstens ausserordentlich gering (Versuch 49, 50, 59 und 60).

Zusammenfassend zu sagen, wirkt der Maskenapparat auf den Kompensationsakt der Atmungsfläche der Lunge, wenn auch in geringem Masse, doch oft verhältnismüssig deutlich ein, d. h. die Atmungszahl wird manchmal durch ihn vermindert, während er mit der Veränderung des Blutes gar nichts zu tun hat.

\section{G. Einflüsse des Atmens von reinem Sauerstoff auf Atmungsty pus und Blut.}

In der ersten Mitteilung erwähnte ich schon, wie beide Faktoren, Überdruck und Sauerstoff, auf die von dem Überdruckatmen verursachte Blutverdünnungserscheinung wirkt. Um die Tatsache noch überzeugender zu bestätigen, dass Blutverdünnungserscheinung nichts anderes als physiologische Anpassung gegen Sauerstoffaufnahme ist (siehe 1. Mitteilung), fügte ich hier die Ergebnisse meiner Kontrollversuche bei. In der Literatur ist eine Fülle von Berichten über Experimente vorhanden, die sich mit eventuellen Einflüssen des reinen Sauerstoffes oder des mit diesem gemischten Gases auf den Sauerstoffverbrauch den partiellen Sauerstoffdruck in den Alveolen oder den auf das Blutgas eines Organismus beschäftigen. Die Ergebnisse all dieser Experimente stimmten darin überein, dass jene Faktoren so lange mit diesen nichts zu tun haben, wie noch irgendwelche vermehrte Verbrennungsprozesse innerhalb des Organismus vor sich gehen. Trotzdem soll nach dem Ergebnis der Experimente über Sauerstoffinhalation von $\mathrm{Ka} \mathrm{to}^{15)}$ ausser dem mit Hämoglobin verbundenen Sauerstoff auch die physikalisch gelöste Sauerstoffmenge ein wichtiges Element sein, im Fall, wo der partielle Druck sehr gross ist ; er stellte dabei auch fest, dass Sauerstoffinbalation die Wirkung hat, die Sauerstoffunsättigung bei ge- 
sunden Menschen unter die Norm herabzusetzen.

Anderseits fehlt es an auf Experimente gegründeten Mitteilungen, die den Einfluss des Sauerstoffes, den dieser auf Zu- und Abnahme der Atmungsoberfläche hat, behandeln ; deshalb möchte ich durch die von mir unternommene Kontrollversuche einiges Licht auf dieses Gebiet werfen.

Aus den Ergebnissen meiner Experimente geht hervor, dass sowohl bei Hunden als Kaninchen die Abnahme der Atmungszahl, Atmungstiefe, des Hämoglobingehaltes und der Serumeiweissmenge ganz ausserordentlich gross, nur aber viel langsamer ist als beim Uberdruckatmen; es braucht nämlich sehr oft wenigstens 5-30 Minuten, bis sie eintritt (Versuch 52, Figg. 18 bis 21).

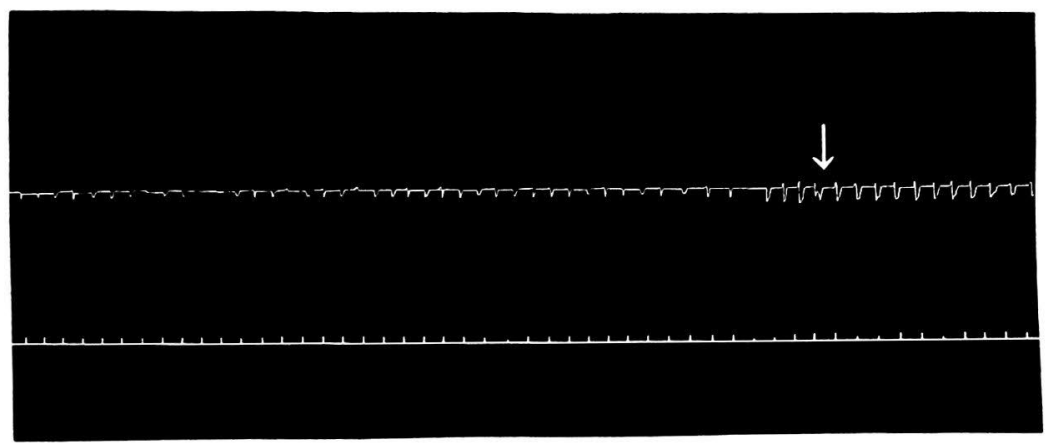

Fig. 18. Hund Nr. 29, $\hat{\delta}$, schwarz, $3,26 \mathrm{~kg}$. 28. November 1925, Zimmertemperatur $18^{\circ} \mathrm{C}$. Sauerstoffatmung, 10 Minuten lang. (Versuch 57). Kurve : vor und direkt nach d. Sauerstoffatmung. Pfeil : Beginn d. Sauerstoffatmung. Zeitmark in 5 Sekunden.

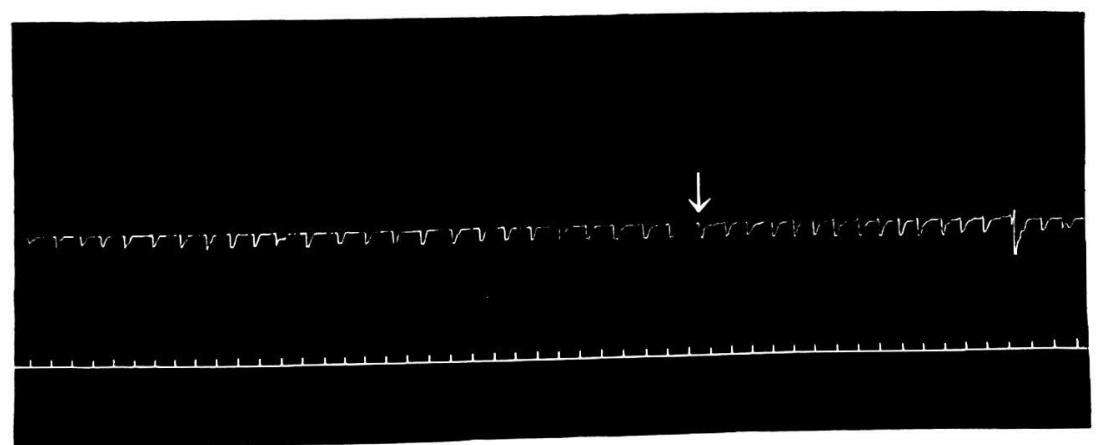

Fig. 19. Hund Nr. 28, ô, 17,4 kg. 14. November 1925, Zimmertemperatur $16^{\circ} \mathrm{C}$. Atmung mit reinem Sauerstoff, 30 Minuten lang (Versuch 55). Kurve: am Anfang d. Sauerstoffatmung. Pfeil : Beginn d. Sauerstoffatmung. 


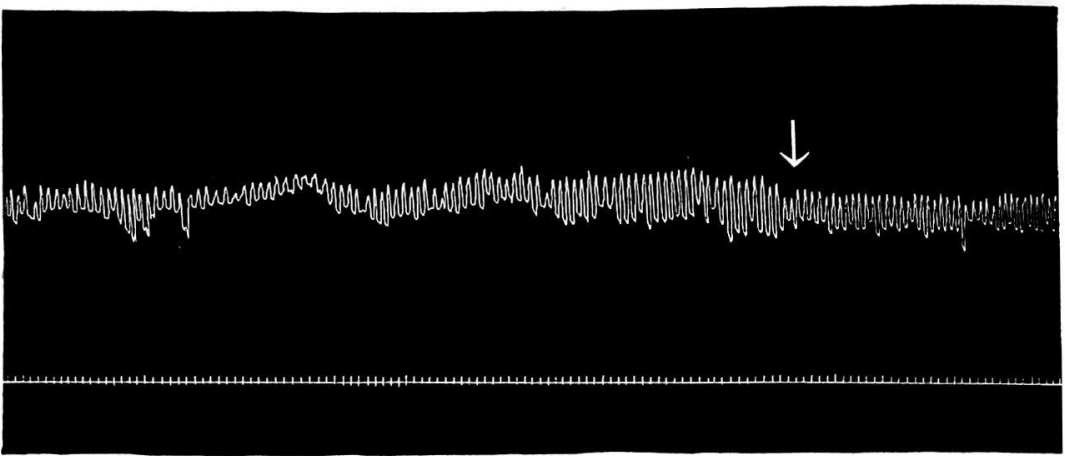

Fig. 20. Kaninchen Nr. 24, 合, $1890 \mathrm{~g}$. 18. Oktober 1925 , Zimmertemperatur $16^{\circ} \mathrm{C}$. Atmung mit reinem Sauerstoff, 15 Minuten lang. Direkt nach d. Sauerstoffatmung. Pfeil : Beginn d. Sauerstoffzufuhr. Zeitmark in 2 Sekunden.

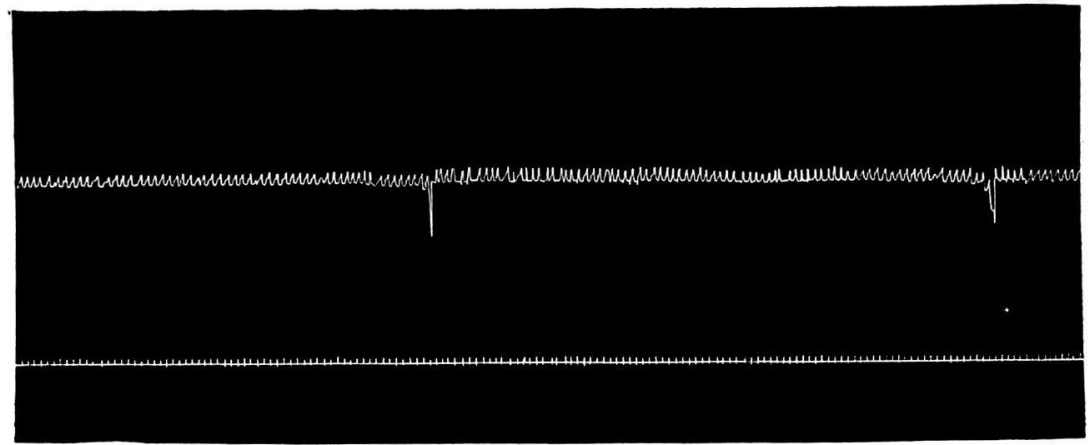

Fig. 21. Ca 10 Minuten später von Kurve bei Fig. 20.

Versuch 52. Hund Nr. 25, ㅇ, weiss, 7,4 kg. Morphin-Narkose. 19. Oktober 1925, Zimmertemperatur $17^{\circ} \mathrm{C}$. Atmung mit reinem Sauerstoff, 30 Minuten lang. Blutentnahme aus Ohrarterien.

\begin{tabular}{l|c|c|c}
\hline Zeit & $\begin{array}{c}\text { Atemzahl } \\
\text { (per Min.) }\end{array}$ & $\begin{array}{c}\text { Atemtiefe } \\
\text { (mm) }\end{array}$ & $\begin{array}{c}\text { Hämoglo- } \\
\text { bingehalt } \\
\text { (Sahli) }\end{array}$ \\
\hline Vor d. Sauerstoff-Atmung & $9-10$ & 1,5 & 87 \\
9 Minuten nach Sauerstoffatmung & 11 & 1,5 & 85 \\
16 Minuten später & 11 & 1,5 & 83 \\
21 " " $" 11$ & 1,5 & 83 \\
4 Min." nach Schluss d. Sauerstoffes & 10 & 1,5 & 80 \\
10 Minuten später & 10 & 1,5 & 80 \\
& & 1,5 & 83
\end{tabular}


Das kowmt wahrscheinlich daher dass in diesem Fall, anders als beim Überdruckatmen, die Atmung nur unter atmosphärischem Druck ausgeführt wird und infolgedessen die Lungenalveolen davor bewahrt bleiben, sich gewaltsam zu erweitern.

Die obige Abnahmeerscheinung gilt immer für die Fälle, wo das 'Tier hämoglobinreich ist, z. B. bei Hunden gegen oder über $100 \%$. Dagegen komnt es im anämischen Fall, d. h. unter 70\% Hb., zu keiner Terdünnungserscheinung, gleichfalls verlangsamt sich weder das Atmen noch wird es oberflïchlich.

Versuch 53. Hund Nr. 26, o, schwäralich-briunlich, $8,3 \mathrm{~kg} . \quad 30$. Oktober 1925 , Zimmertemperatur $17^{\circ} \mathrm{C}$. Blutentnahme aus Ohrarterie. Atmung mit reinem Sauerstoff, 20 Minuten lang.

\begin{tabular}{l|c|c|c|c}
\hline \multicolumn{1}{c|}{ Zeit } & $\begin{array}{c}\text { Atemzahl } \\
\text { (per Min.) }\end{array}$ & $\begin{array}{c}\text { Atemtiefe } \\
\text { (nm) }\end{array}$ & $\begin{array}{c}\text { Hïmoglo- } \\
\text { bingehalt } \\
\text { (Sahli) }\end{array}$ & $\begin{array}{c}\text { Serum- } \\
\text { eiweiss } \\
(06)\end{array}$ \\
\hline Vor d. Maskenanwendung & 11 & - & 70 & 6,984 \\
Vor d. Sauerstoffatmung & 9 & 3 & 70 & 6,984 \\
8 Min. nach d. Sauerstofiatmung & 8 & 3 & 70 & 6,984 \\
18 Min. spüter & 9 & 3 & 71 & 6,984 \\
2Min. nach Schlus d. Sauerstoff- & 9 & 3 & 68 & 6,984 \\
atmung & 10 & - & 70 & 6,984 \\
10 Min. später & & &
\end{tabular}

Keine nennenswerte Verïnderungen an Atmung und Blut. Es war bemerkenswert, dass der Hund ziemlich an:inisch war.

Versuch 57. Hund Nr. 29, $\hat{\delta}$, schwarz, $3,26 \mathrm{~kg}$. Morphin Narkose. 28. November 1925. Zimmertemperatur $18^{\circ} \mathrm{C}$. Sauerstoffatmung, 10 Min. lang Blutentnahme aus Ohrarterie.

\begin{tabular}{l|c|c|c|c}
\hline \multicolumn{1}{c|}{ Zeit } & $\begin{array}{c}\text { Atemzahl } \\
\text { (per Min.) }\end{array}$ & $\begin{array}{c}\text { Atemtiefe } \\
(\mathrm{mm})\end{array}$ & $\begin{array}{c}\text { Hämoglo- } \\
\text { bingehalt } \\
\text { (Sahli) }\end{array}$ & $\begin{array}{c}\text { Serum- } \\
\text { eiweiss } \\
(0 \%)\end{array}$ \\
\hline Vor d. Sauerstoff & 14 & 4 & 62 & 7,200 \\
3 Min. nach Sauerstoff & 8 & 2 & 62 & - \\
7 Min. spïter & 9 & 1,5 & 63 & 7,200 \\
2 Min. nach Schluss d. Sauerstoff & 13 & 3 & 63 & 7,200 \\
15 Min. spüter & 13 & - & 62 & 7
\end{tabular}

Nur an Atmung typische Verïnderung beobachtet. Kurve.

Fig. 18.

Selbst in Verdünnungfall tritt, wenn man genauer beobachtet, die Verminderung an Hämoglobin verhältnismüssig langsamer ein als sonst (Versuch 52 u. 61). 
Versuch 61. Kaninchen Nr. 23, $\{, 166$ g. Ohne Narkose. 7. Oktober 1925, Zimmertemperatur $15^{\circ} \mathrm{C}$. Atmung mit reinem Sauerstoff (1 Atomosphären Druck), 15 Minuten lang, Blutentnahme aus Oharkapillaren.

\begin{tabular}{|c|c|c|c|c|c|}
\hline Zeit & $\begin{array}{r}\text { Atemzahl } \\
\text { (per Min.) }\end{array}$ & $\begin{array}{l}\text { Atemtiefe } \\
(\mathrm{mm})\end{array}$ & $\begin{array}{l}\text { Hïmoglo- } \\
\text { bingehalt } \\
\text { (Sahli) }\end{array}$ & $\begin{array}{l}\text { Serum- } \\
\text { eiweiss } \\
(\%)\end{array}$ & $\begin{array}{l}\text { Serum- } \\
\text { chlorid } \\
(\%)\end{array}$ \\
\hline $\begin{array}{l}\text { Vor d. Sauerstoffatmung } \\
3 \text { Min. nach Sauerstoffatmung } \\
3 \text { Minuten später } \\
9 \text { ". } \\
2 \text { Min. nach S̈chluss d. Sauer- } \\
\text { stoffatmung } \\
10 \text { Minuten später }\end{array}$ & $\begin{array}{l}74 \\
65 \\
60 \\
62 \\
74 \\
70\end{array}$ & $\begin{array}{l}7 \\
4 \\
2,5 \\
1,5 \\
7\end{array}$ & $\begin{array}{l}72 \\
68 \\
70 \\
67 \\
68 \\
70\end{array}$ & $\begin{array}{l}6,120 \\
\overline{5} \\
5,902 \\
= \\
6,120\end{array}$ & $\begin{array}{l}0,577 \\
\frac{-}{0,577} \\
- \\
0,613\end{array}$ \\
\hline
\end{tabular}

Deutliche Veränderung an Atmung und Blut.

Um es nochmals zu wiederholen, bei der Inhalation des reinen Sauerstoffes tritt nur dann Veränderung des Blutes sowie des Atmens ganz deutlich ein, wenn das betreffende Tier hämoglobinreich ist.

\section{Deutung der Ergebnisse und Schlussfolgerung.}

Aus den Ergebnissen meiner Versuche ist folglich ersichtlich, dass wie bei Menschen auch bei Hunden und Kaninchen durch Anwendung von Überdruckatmung (Luft und Sauerstoff) ganz deutlich Blutverdünnung stattfindet, und dass es sogar möglich ist, dass unter den bestimmten Bedingungen durch Unterdruckatmung Blutverdickung auftritt. Es ist also sicher nachgewiesen, dass bei beiden Arten von Druckdifferenzatmung Veränderung an Zahl der roten Blutkörperchen und Hämoglobingehalt durch den Austauch des Gewebssaftes zwischen Gewebe und Zirkulationssystem verursacht wird. Weiter gebèn uns die Kontrollversuche einen klaren Nachweis dafür, dass diese Veründerung nichts anders als eine physiologische Anpassungserscheinung d. h. die Regulation der Atmungsoberfläche des Blutes ist, welche schon am Schluss meiner I. Mitteilung in Frage stand. Ausserdem zeitigt diese II. Mitteilung das Ergebnis, dass die Erscheinungen des Blutes mit der Regulation durch Atmung in ganz inniger Beziehung stehen. Deshalb kann man sagen, dass zwischen der Atmungsoberfläche von Blut und Lunge ein Kompensationsmechanismus wirkt.

Seit Rosenthal (16) ist es allgemein bestätigt, dass das Atemzentrum gegen Sauerstoff und Kohlensäure in den Alveolen äusserst empfindlich ist, und dass die vollständige Atemlosigkeit einen Stillstand der Atembewegung bei totalem Mangel an Kohlensäure bedeutet. Schon durch Hook und Ro- 
senthal wurde temporäre Atemlosigkeit bei forcierter Atmung an Menschen sowie an Kaninchen experimentell festgestellt. Aber hieran anschliessend behaupten Gaad, Knoll, Eisenhardt und andere, dass die Veränderung des Blutgases bei Lufteinblasung nicht die einzige Ursache der Atemlosigkeit sei, sondern dass eine forcierte Dehnung der Endzweige von Lungenvagus eine grosse Rolle spielt, wodurch reflektorisch die Erregbarkeit des Atemzentrums herabmindert.

Leider fand man bis jetzt keine absolut reizlose Methode für die Ausschaltung des Lungenvagus. Doch von mehreren Standpunkten aus ist die Atemlosigkeit nach Miescher-Rusch (18), Eisenhardt (8), Haldane usw. in zwei Hauptoformen eingeteilt, d. h. Apnoea vera und Apnoea spuria.

Nun ist die Veränderung der Atmungsoberflïche des Blutes ein ganz besonderer Regulationsmechanismus, welcher bei normaler Atmung (1 Atmosphärendruck) niemals beobachtet, sondern nur bei abnormer Steigerung oder Verminderung des Partialdruckes des Sauerstoffes in der Luft d. h. bei übermässigem Angebot oder Mangel desselben ausgeführt wird.

Es ist eine interessante Beobachtung, dass im Sinne von Kompensation der Atmungsoberfläche ein inniges Verhältnis zwischen Atembewegung und Blut entsteht :-

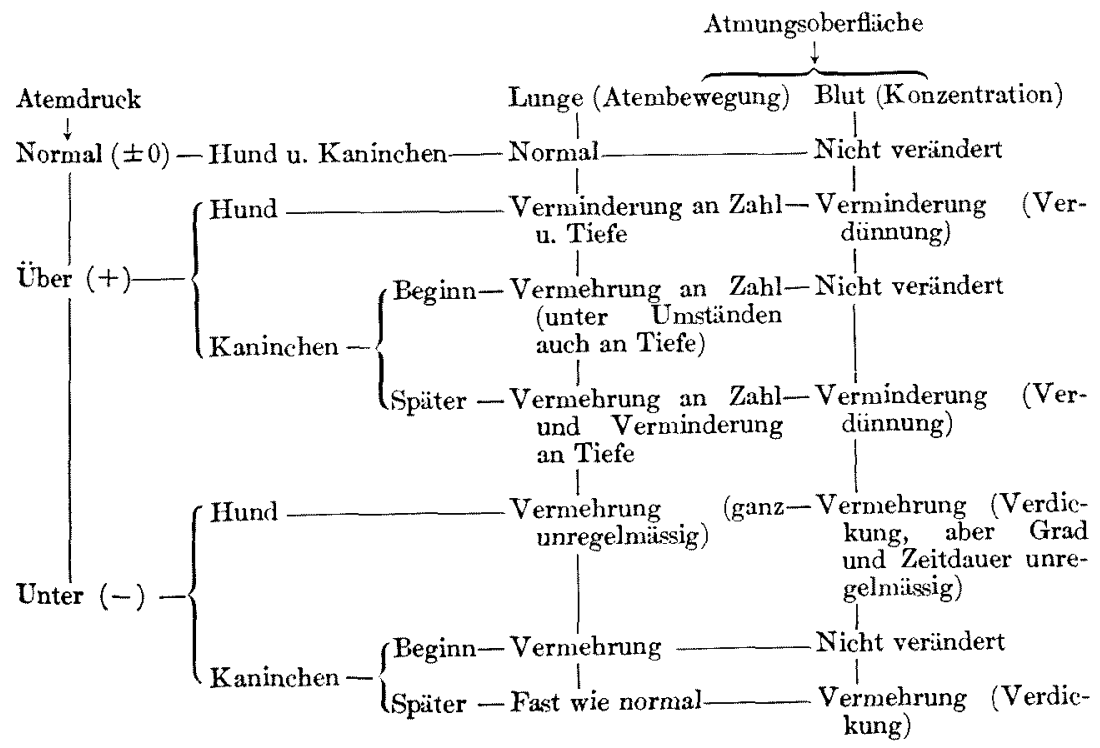




\section{Zusammenfassung.}

(1) Wie bei Menschen wird auch bei Tieren (Hund und Kaninchen) durch plötzliche Anwendung des Überdruckatmens Blutverdünnung herbei geführt.

(2) Atmung von reinem Sauerstoff (1 Atmosphärendruck) erzielt das gleiche Ergebnis.

(3) Diese Verdünnungserscheinung des Blutes kann man als einen Regulationsmechanismus der Atmungsoberfläche des Blutes betrachten, die unter irgend einer Bedingung z. B. bei Anämie nicht stattfindet.

(4) Unter Umständen, sogar auch bei Unterdruckatmen, kommtBlutverdickung vor, welche auch als eine Regulationserscheinung anzusehen ist.

(5) Bei der abnormen Veränderung des Partialdruckes des Sauerstoffes in der Iuft stellt die Kompensation durch Atmungsoberfläche der Lunge und des Blutes ein sehr inniges Verhältnis dar.

(6) Veränderung der Blutkonzentration bei Über- oder Unterdruckatmen wird durch den Wasseraustausch zwischen Gewebe und Blut herbeiführt.

\section{Literatur.}

(1) I zu m i y a ma, Nippon Gekagakkai Zasshi (japanisch), 1924, 25, 226.

(2) Derselbe, Nippon Gekagakkai Zasshi (japanisch), 1925, 26, 301.

(3) Moog und Pelling, Deut. med. Wochenschr., 1925, 51, 984.

(4) Dünner und Mecklllenburg, Deut. med. Wochenschr., 1925, 51, 1231.

(5) I z u mi y a ma, Nippon Gekagakki Zasshi (japanisch), 1926, 27, 1649.

(6) Derselbe, Sitzungsbericht vom 26. chirur. Kongress in Japan, 1925.

(7) Moteki, Sitzungsbericht rom 22. med. Kongress in Japan.

(8) Eisenhardt, Arch. f. gesamt. Physiol., 1912, 146, 446.

(9) Fränkel, Münch. med. Wochenschr., 1899, 1524.

(10) Mïller, Annales de Chemie et de Physique, 1858, 108. Cf. nach Lan do is' Lehrbuch d. Physiol., 1921, 17, Aufl.

(11) Hough, Amer. Journal of Physiol., 1910, 26, 1659.

(12) Lei m dör fer, Bioch. Zeitschr., 1909, $12,45$.

(13) Cohnstein und $Z$ un $z$, Pfliigers Arch., 1888, 42, 303.

(14) Rosem an n, Lando is' Lehrbuch d. Physiol., 1921, 17. Auf. 185.

(15) Toyojiro Kat o, Nippon Naikagakkai Zasshi (japanisch), 1921, 9, 705.

(16) Rosenthal, Arch. f. (Anatom. u.) Physiol., 1865, 191.

(17) Gaad, Dasselbe Arch. 1880, 28.

(1S) Miescher und Rusch, Dasselbe Arch. 1885, 355.

Zum Schluss spreche ich meinem hochverehrten Lehrer, Herrn Prof. Dr. Sekiguchi meinen aufrichtigsten Dank fïr seine Unterstützung bei der Anlegung dieser Arbeit aus. 